\title{
Top-down expectancy versus bottom-up guidance in search for known color-form conjunctions
}

\author{
Giles M. Anderson ${ }^{1}$ - Glyn W. Humphreys ${ }^{2}$
}

Published online: 22 July 2015

(C) The Psychonomic Society, Inc. 2015

\begin{abstract}
We assessed the effects of pairing a target object with its familiar color on eye movements in visual search, under conditions where the familiar color could or could not be predicted. In Experiment 1 participants searched for a yellow- or purple-colored corn target amongst aubergine distractors, half of which were yellow and half purple. Search was more efficient when the color of the target was familiar and early eye movements more likely to be directed to targets carrying a familiar color than an unfamiliar color. Experiment 2 introduced cues which predicted the target color at $80 \%$ validity. Cue validity did not affect whether early fixations were to the target. Invalid cues, however, disrupted search efficiency for targets in an unfamiliar color whilst there was little cost to search efficiency for targets in their familiar color. These results generalized across items with different colors (Experiment 3). The data are consistent with early processes in selection being automatically modulated in a bottom-up manner to targets in their familiar color, even when expectancies are set for other colors.
\end{abstract}

Keywords Visual search · Eye movements and visual attention $\cdot$ Visual perception

Giles M. Anderson

giles@gilesanderson.co.uk

Glyn W. Humphreys

glyn.humphreys@psy.ox.ac.uk

1 Department of Psychology, Oxford Brookes University, Oxford OX3 0BP, UK

2 Department of Experimental Psychology, University of Oxford, Oxford OX1 3UD, UK

\section{Introduction}

There is a large body of research on visual search indicating that search efficiency is determined by visual differences between targets and distractors and also between the distractors themselves (e.g., Duncan \& Humphreys, 1989; Wolfe, 2003). There has been much less work into how search is modulated by the stored knowledge the observer can call upon to direct search. Nevertheless, there is evidence that stored knowledge mediates search efficiency, reflected in effects of stimulus familiarity on performance. For example, search for a 2 target amongst $\mathbf{5}$ distractors is easier than when the items are rotated by $90^{\circ}$ (Wang, Cavanagh, \& Green, 1994), indicating that the familiarity of the distractors facilitates how easily they can be rejected in a search. Similarly, search for a target can be facilitated if participants hear the sounds the target makes during the search process (Iordanescu, Grabowecky, Franconeri, Theeuwes, \& Suzuki, 2010). In addition, search for a target is influenced by the presence of semantically related distractors, even when the target is absent from the display (Belke, Humphreys, Watson, Meyer, \& Telling, 2008; Moores, Laiti, \& Chelazzi, 2003; Telling, Kumar, Meyer, \& Humphreys, 2009) - consistent with stored representations for items related to an expected target affecting the search process. Recent work has also shown that presenting an object in its familiar color can also moderate a search, even when color is irrelevant for the task (Rappaport, Riddoch, \& Humphreys, 2013, see also Wildegger, Riddoch, \& Humphreys, 2015). The present paper focuses on this latter result, using eye movements to assess the microgenesis of a search within a trial. We ask whether presenting an object in its familiar color modulates the early eye movements on a trial, consistent with the familiar combination of the colored shape affecting early selection processes. In addition, we evaluate whether the familiarly colored target shape can direct the early stages of 
search even when that item is not expected. Furthermore, we investigate whether introducing expectations about the target alters the effect of target-familiarity on the progression of search.

Questions about how search proceeds for colored shapes are theoretically important as major theories of visual attention, such as Feature Integration Theory (Treisman, 1998), hold that a critical constraint on search is whether targets are distinguished by the presence of a single feature difference relative to distractors, or whether items differ in the conjunction of features (e.g., color and form). Search for targets defined by a conjunction of features is often inefficient, consistent with participants needing to attend to each item in order to bind their features (e.g., the color with the form). Other theories, such as the Guided Search Theory, propose that a conjunction search can be guided by parallel processes rather than being of a serial nature (see Wolfe, Cave, \& Franzel, 1989). Recent data suggest that search for familiar color-form conjunctions (e.g., when objects carry their familiar color) can also operate in a parallel manner. Rappaport et al. (2013) asked participants to search for an image of a corn target which appeared amongst carrot, aubergine, and lemon distractors. Some of the shapes were similar to those of the target (e.g., aubergine and carrot) and the distractors could carry the color of the target. When the target was in an unfamiliar color, search was slow and strongly affected by the number of distractors present - a pattern of inefficient search typical of conjunction search tasks. However, when the target carried its familiar color, search was efficient (the slope of the search functions was less than $10 \mathrm{~ms} /$ item). Rappaport et al. (2013) proposed that stored knowledge of the familiar colorobject relationship enabled the color and form of the target to be bound rapidly and without the attentional constraints evident when the color-form relations were unfamiliar. Search could then be guided efficiently to the familiar color-form conjunction. Rappaport et al. (2013) also suggested that this rapid binding of familiar color and form, and subsequent guidance of search, took place automatically. They ran one study (Experiment 3) in which the target was much more likely to carry an unfamiliar than a familiar color. The target in the familiar color was still found efficiently although participants tended to look to distractors carrying the expected color rather than those with the target's usual color (e.g., if a purple corn was expected, participants looked at purple rather than yellow distractors, when the target was absent). Thus search was efficient for the familiar color-form conjunction even when expectancies were set for another color. Wildegger et al. (2015) have extended these results using short presentations of search displays and demonstrating effects of familiarly colored targets on perceptual sensitivity.

In the current study we used eye movement analyses to explore the robustness of the above assertion - that there is efficient binding of shape and familiar color - by investigating the microgenesis of search for targets defined by their familiar shape and we varied whether the color of the targets was familiar or not. In addition, we cued participants to expect targets in a particular color and asked whether there was an asymmetry in the cueing effects for targets in familiar and unfamiliar colors (Experiments 2 and 3).

Search was always for a shape singleton and so item color might not be expected to modulate performance. The initial study allows us to measure whether the irrelevant color of the target influences behavior and, if so, to map out the timeline of its influence on guidance during search. Following Rappaport et al. (2013), in Experiment 1 we expect search to be quicker and more efficient for familiar compared to unfamiliar colored targets (e.g., better performance for yellow vs. purple corn amongst yellow and purple aubergine distractors). Search may be directed to the targets when it is a familiar color compared to when it is an unfamiliar color, thereby facilitating search for, in the case of Experiment 1, yellow targets.

\section{Experiment 1: Uncued search for yellow or purple corn}

Four blocks of search trials were undertaken during which participants were required to search for a corn target amongst aubergine distractors. Although color was irrelevant to the task, targets could carry either a familiar color (yellow) or an unfamiliar color (purple), whilst sharing this feature with half the aubergine distractors. The array size was varied, allowing search speed and efficiency to be measured (e.g., the latter reflected by increases in search time/accuracy per additional item). Eye movements were recorded on each trial. We asked whether there was an advantage for targets with a familiar relative to an unfamiliar color, whether this was reflected in a shift in search efficiency (the array size effect), and whether the effect emerged with practice or was present from the start of the study. We were also interested in the degree to which first and second fixations are directed to familiar compared to unfamiliar targets. The frequency at which initial fixations are directed to the target can offer an index of bottom-up biases (cf. Van Zoest, Donk, \& Theewes, 2004) whilst secondary fixations may indicate later guidance or redirection of overt attention

\section{Method}

\section{Participants}

Twenty undergraduates from Oxford Brookes University, five male, aged 18-39 years (mean 22.05 years) took part for course credits. 


\section{Design}

The experiment had a a three-factor between-participants design: block number (one to four) $\times$ target color (yellow or purple) $\times$ array size (seven or 13 ).

\section{Stimuli}

All the stimuli were presented on a grey background. The drift correction stimulus was a black circle with 4-mm diameter (visual angle of $.35^{\circ}$ at $650-\mathrm{mm}$ viewing distance), while the fixation cross was a black "+," $3 \mathrm{~cm}\left(.26^{\circ}\right)$ wide and $3 \mathrm{~cm}$ $\left(.26^{\circ}\right)$ high. A word stimulus "NEUTRAL" was presented before the search display, $24 \mathrm{~mm}$ wide (a visual angle of $\left.2.12^{\circ}\right)$ and $4 \mathrm{~mm}$ tall $\left(.35^{\circ}\right)$. The mask stimulus was a string of “\#”s, $35 \mathrm{~mm}$ long $\left(2.20^{\circ}\right)$ and $6 \mathrm{~mm}$ tall $\left(.53^{\circ}\right)$. All letters were presented in black capitals using an Arial font. The stimuli were either yellow or purple corns or yellow or purple aubergines, and are identical to those used in Rappaport et al. (2013). Examples are shown in Fig. 1. The ranges of CIE (International Commission on Illumination) color coordinates for each color used for each stimulus and the background are outlined in Table 1.

All images were tilted at $45^{\circ}$, either left or right. Corn images were $18 \mathrm{~mm}$ long $\left(1.59^{\circ}\right)$ and $6 \mathrm{~mm}\left(.53^{\circ}\right)$ wide, while aubergine images were $16 \mathrm{~mm}$ long $\left(1.41^{\circ}\right)$ and $7 \mathrm{~mm}\left(.62^{\circ}\right)$ wide.

\section{Apparatus}

All the stimuli were presented on a display PC with a 23.6-in 16:9 color LED LCD monitor $(520 \mathrm{~mm} \times 290 \mathrm{~mm}$, BenQ XL2410T). The stimuli were generated by the Experiment Builder program (SR Research, Mississauga, Ontario, Canada) at a screen resolution of $1,920 \times 1,080$. Audio feedback was provided by stereo Logitech speakers. Participants placed their head on a chin rest $650 \mathrm{~mm}$ from the screen, in a dimly lit room with windows blacked-out to avoid luminance changes. Chin rest and monitor heights were adjusted so eye gaze was central to the display screen. Response times (RTs) and accuracy were recorded via a standard PC mouse. Eye movements were recorded using an Eyelink 1000 system, running at a spatial accuracy of $.25^{\circ}-.5^{\circ}$, a spatial resolution of $.01^{\circ}$, and a temporal resolution of $1 \mathrm{~ms}(1,000 \mathrm{~Hz})$. The eye-tracking
Table 1 The CIE color coordinates of a range of the yellow and purple shades used in the corn and aubergine stimuli in all experiments as measured by a ColorCal (Mk II) Colorimeter, manufactured by Cambridge Research Systems (CRS: http://www.crsltd.com/). Values for the gray display background were also included

\begin{tabular}{|c|c|c|c|c|c|c|}
\hline & \multicolumn{3}{|l|}{ Corn } & \multicolumn{3}{|c|}{ Aubergine } \\
\hline & $\mathrm{Cd} / \mathrm{m}^{2}$ & $\mathrm{x}$ & $\mathrm{y}$ & $\mathrm{Cd} / \mathrm{m}^{2}$ & $\mathrm{x}$ & $\mathrm{y}$ \\
\hline Dark purple & 3.29 & .34 & .27 & 2.83 & .31 & .20 \\
\hline Medium purple & 9.06 & .32 & .22 & 4.60 & .32 & .21 \\
\hline Light purple & 23.20 & .31 & .25 & 25.27 & .31 & .27 \\
\hline Dark yellow & 20.81 & .48 & .43 & 43.94 & .50 & .45 \\
\hline Medium yellow & 47.01 & .46 & .46 & 50.16 & .48 & .47 \\
\hline Light yellow & 61.52 & .41 & .43 & 70.34 & .36 & .39 \\
\hline Gray (background) & 58.3 & .31 & .31 & 58.3 & .31 & .31 \\
\hline
\end{tabular}

camera was linked to a separate $\mathrm{PC}$ to the one displaying the search stimuli. EyeLink software (SR Research) was used to control the camera and collect data, and was synchronized via an Ethernet cable with the display PC.

\section{Procedure}

Calibration was performed prior to each experimental block, as well as mid-block if necessary. A drift correction to the calibration was made prior to each trial. Following the drift correction, a fixation cross was presented for $1,000 \mathrm{~ms}$, then the word "NEUTRAL" (1,000-ms duration), a mask (200-ms duration), then the item array. The display was presented until participants responded with a mouse click. Either seven or 13 items were presented in 15 possible positions, with these positions in an approximate invisible circle with a diameter of around $184 \mathrm{~mm}\left(55.5^{\circ}\right)$. Positions were jittered $\left( \pm 0.1^{\circ}\right)$ vertically and horizontally to lessen spatial interactions between items (see Fig. 2 for examples). The target could be yellow or purple, and tilted to the left or the right, whilst the distractors were $50 \%$ yellow aubergines, $50 \%$ purple aubergines. Half the distractors were tilted to the left, half to the right, and this factor was varied orthogonally to distractor color. Within this display, participants looked for a corn-shaped target amongst aubergine-shaped distractors as quickly and accurately as possible, and pressed the mouse button that matched the side that the top of the target was tilted toward (e.g., tilted to the left,

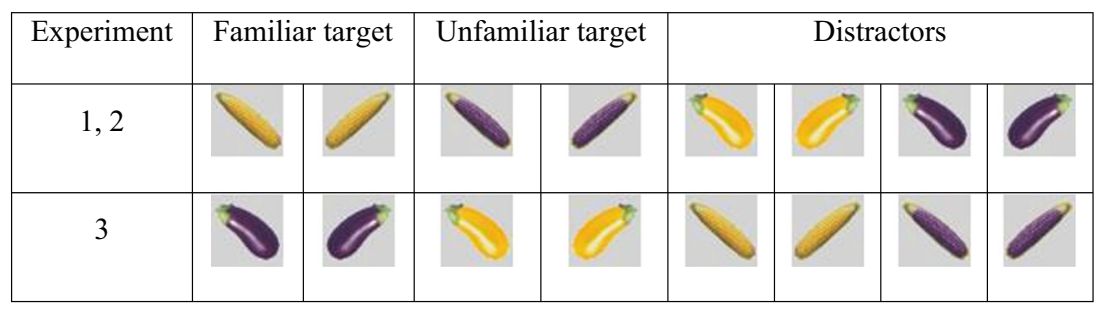

Fig. 1 Targets and distractors used on all experiments 


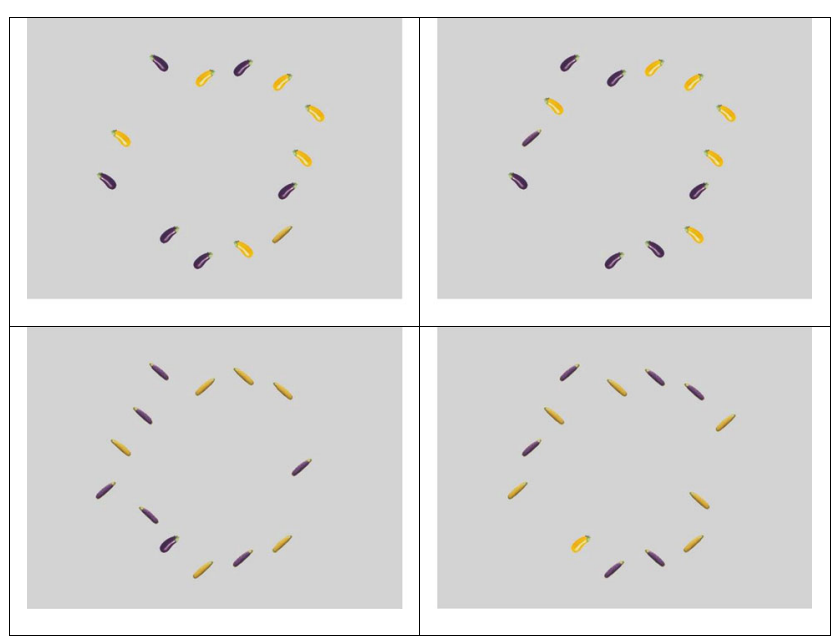

Fig. 2 Examples from Experiments 1 and 2 (top row) and Experiment 3 (bottom row) of 13-item displays with familiar targets (left column) and unfamiliar targets (right column). Seven-item displays were also presented

press the left mouse button). Accuracy was also emphasized with audio feedback provided. If the response was correct, participants heard a medium-pitched sound and the word "Correct" was displayed. If the response was incorrect, a lower note was played and the word "Incorrect" was displayed instead.

Participants took part in a practice block of 20 trials during which the data were not recorded, followed by four blocks of 80 trials. The time until each participant's response was recorded (RT), with the accuracy of the response also noted. The positions of eye fixations were also recorded during the search task.

\section{Results}

For all analyses, Greenhouse-Geisser adjustments were used where necessary to control the family-wise error rate. All pairwise comparisons included Bonferroni adjustments and were measured as significant at the $\mathrm{p}<.05$ level.

\section{Response times (RTs)}

In Experiment 1, we were interested in establishing the advantage for search for a familiar colored target over a target in an unfamiliar color, and whether this benefit was robust with practice. There was a trade-off of speed and accuracy in Experiment 3. It was therefore decided that, across experiments, RTs would be adjusted by dividing median RTs of correct trials for each participant for each target color and array size, by the corresponding mean accuracy (see Rappaport et al., 2013). Group means are shown in Fig. 3. For parsimony, we only analyzed data from the first and last blocks (block 1 and block 4), although data from blocks 2 and 3 are also presented in the figure.

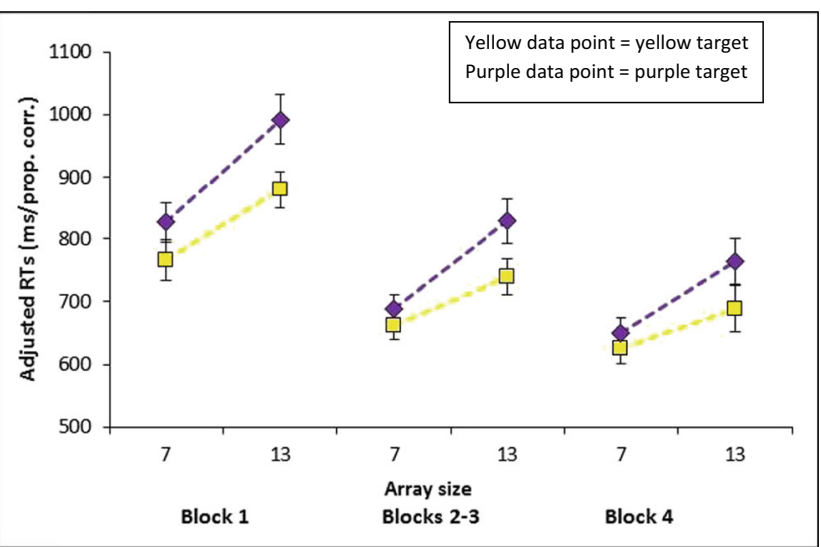

Fig. 3 Mean adjusted response times (RTs) $( \pm 1$ standard error) in Experiment 1, split by block (although data from blocks 2 and 3 were merged and are only shown for completeness), target color, and array size. Adjusted RTs were calculated by dividing RTs with the relevant accuracy measure

\section{Blocks 1 and 4}

There were main effects of block $(\mathrm{F}(1,19)=194.557, \mathrm{p}<.001$, partial $\left.\eta^{2}=.911\right)$, array size $(\mathrm{F}(1,19)=94.221, \mathrm{p}<.001$, partial $\left.\eta^{2}=.832\right)$, and target color $(\mathrm{F}(1,19)=27.608, \mathrm{p}<$ .001 , partial $\left.\eta^{2}=.592\right)$. RTs were quicker in block 4 compared to block 1 (682 ms vs. $866 \mathrm{~ms})$, for seven-item compared to 13-item displays (717 ms vs. $831 \mathrm{~ms}$ ), and for yellow compared to purple targets ( $740 \mathrm{~ms}$ vs. $808 \mathrm{~ms})$. There were also two interactions: block $\times$ array size $(\mathrm{F}(1,19)=8.038, \mathrm{p}=.011$, partial $\left.\eta^{2}=.297\right)$ and array size $\times$ target color $(\mathrm{F}(1,19)=$ $5.454, \mathrm{p}=.031$, partial $\eta^{2}=.223$ ). The block $\times$ array size interaction was due to the search efficiency (RTs $\times$ array size) improving across blocks (block 1 , an effect of array size of $140 \mathrm{~ms}, \mathrm{p}<.001$, overall search slopes of $23 \mathrm{~ms} /$ item, vs. block 4, an effect of array size of $88 \mathrm{~ms}, \mathrm{p}<.001,15 \mathrm{~ms} /$ item $)$. The array size $\times$ target color interaction reflected more efficient search for yellow relative to purple targets (yellow target, effect of array size of $88 \mathrm{~ms}$, slope of $15 \mathrm{~ms} /$ item vs. purple target, an effect of array size of $140 \mathrm{~ms}, \mathrm{p}<.001$, slope of $23 \mathrm{~ms} /$ item, respectively).

\section{Fixations}

We analyzed the first two fixations to the search displays on correct response trials. Fixations were recorded when the eye movement did not exceed a velocity threshold of $30^{\circ} / \mathrm{sec}$, an acceleration threshold of $8,000^{\circ} / \mathrm{sec}^{2}$, or a motion threshold of $.1^{\circ}$, and the pupil was not missing for more than three samples in a sequence. The latter excludes data recorded during eye blinks and, as a consequence, less than $1 \%$ of fixations were removed across all experiments. Fixations detected within $80 \mathrm{~ms}$ of array onset were deemed preparatory and discarded 
(see van Zoest, Donk, \& Theeuwes, 2004). Furthermore, trials with fewer than two fixations were discarded. ${ }^{1}$ A reduction of less than $5 \%$ of data resulted for all experiments. A fixation was assigned to a particular item (its nearest) if the Euclidean distance between fixation and item was at a minimum.

\section{Target-fixations ${ }^{2}$}

We determined the mean frequency of fixations nearest to targets for each participant, and values were adjusted for chance by subtracting the likelihood of a fixation landing adjacent to the target on that display size. For example, for a seven-item display target-fixations were adjusted by the subtraction of one-seventh. Group means are shown in Fig. 4.

For clarity, first and second fixations were analyzed separately.

First fixations to targets There were main effects of block $\left(\mathrm{F}(1,19)=29.622, \mathrm{p}<.001\right.$, partial $\left.\eta^{2}=.609\right)$ and target color $\left(\mathrm{F}(1,19)=12.162, \mathrm{p}=.002\right.$, partial $\left.\eta^{2}=.39\right)$. More first fixations were to the target on block 1 compared to block 4 (.012 vs .13), and more first fixations were to familiar compared with unfamiliar targets (.102 vs. .04). The block $\times$ target familiarity interaction did not reach significance $(F(1,19)=$ $1.651, \mathrm{p}=.214$, partial $\eta^{2}=.08$ ).

Second fixations to targets There were main effects of target color $\left(\mathrm{F}(1,19)=78.424, \mathrm{p}<.001\right.$, partial $\left.\eta^{2}=.805\right)$, block $\left(\mathrm{F}(1,19)=62.309, \mathrm{p}<.001\right.$, partial $\left.\eta^{2}=.766\right)$, and array size $\left(\mathrm{F}(1,19)=41.983, \mathrm{p}<.001\right.$, partial $\left.\eta^{2}=.688\right)$. More second fixations were to familiar than unfamiliar targets (.588 vs. .433). In block 4, there were more second fixations to the target than in block 1 (.616 vs. .405), and there were more second fixations to the target on smaller compared to larger arrays (.562 vs. .458). There was also a block $\times$ target color interaction $\left(\mathrm{F}(1,19)=9.88, \mathrm{p}=.005\right.$, partial $\left.\eta^{2}=.342\right)$. The bias in second fixations being directed to the familiar target reduced across blocks, yet remained robustly significant (block 1: a difference across targets of .206, $\mathrm{p}<.001$; block 4 , a difference across targets of $.104, \mathrm{p}=.001$ ).

\section{Duration of first fixation}

Fixation duration has been shown to be indicative of the degree of stimulus-processing required. The number of stimuli

\footnotetext{
${ }^{1}$ Note that throughout this series of experiments this trial exclusion criteria only applied for analyses of eye movement data.

${ }^{2}$ Our main focus in this paper is on fixations to targets rather than distractors, reflecting an editorial view that an analysis of fixations to distractors would not extend the results substantially. We note, however, that when we analyzed first fixations to distractors we found more first fixations to yellow than purple distractors in both block 1 (a difference of $.144, \mathrm{p}=.002)$ and block 4 (a difference of $.097, \mathrm{p}=.01$ ).
}

increases fixation durations whilst prior information about the stimuli decreases the time taken to process both the initial and additional items (Salthouse \& Ellis, 1980). On neutral trials, therefore, we would expect longer durations the larger the display size, but would take variations across other conditions (item fixated, target color, block) to indicate how long is required to process the relevant item.

We therefore measured the length of the first fixation, with mean duration of first eye movements measured for each participant. Fixation durations were determined using the recommended criteria for the Eyelink 1000 eye-tracker as outlined previously. Data were split by nearest item to fixation, target color, block, and array size. Group means are shown in Fig. 5. There were main effects of nearest item to fixation $(F(2,38)=$ $33.684, \mathrm{p}<.001$, partial $\left.\eta^{2}=.639\right)$, block $(\mathrm{F}(1,19)=22.796, \mathrm{p}$ $<.001$, partial $\left.\eta^{2}=.545\right)$, target color $(\mathrm{F}(1,19)=10.384, \mathrm{p}=$ .004 , partial $\left.\eta^{2}=.353\right)$, and array size $(F(1,19)=6.336, p=$ .021 , partial $\left.\eta^{2}=.25\right)$. Target-fixations were longer than fixations to either type of distractor (first fixation to target vs. first fixation to a yellow distractor, a difference of $24 \mathrm{~ms}, \mathrm{p}<.001$; first fixation to target vs. first fixation to a purple distractor, a difference of $26 \mathrm{~ms}, \mathrm{p}<.001$ ), whilst there was no difference in durations of fixations to either type of distractor (first fixation to purple distractor vs. first fixation to yellow distractor, a difference of $2 \mathrm{~ms}, \mathrm{p}=.83$ ). First fixations were longer when the target was purple compared to yellow (129 ms vs. $123 \mathrm{~ms})$. First fixations were longer in block 1 compared to block 4 (133 ms vs. $119 \mathrm{~ms}$ ) and on 13-item compared to seven-item displays (129 ms vs. $123 \mathrm{~ms}$ ).

There was also an interaction between target color and nearest item to fixation $(\mathrm{F}(1.474,28.005)=6.047, \mathrm{p}=.012$, partial $\left.\eta^{2}=.241\right)$. Fixations to distractors were longer when the target was purple compared to when the target was yellow (differences of $9 \mathrm{~ms}, \mathrm{p}=.003$, and $15 \mathrm{~ms}, \mathrm{p}=.001$, respectively). There was no effect of target color on duration of fixations to the target (a difference of $5 \mathrm{~ms}, \mathrm{p}=.316$ ). The nature of this interaction did not change across block (target color $\times$ nearest item to fixation $\times$ block: $\mathrm{F}(2,38)=.745, \mathrm{p}=$ .482, partial $\eta^{2}=.038$ ).

The above data indicate that increased processing of distractors was required when the target carried an unfamiliar color (in this case purple), suggesting that distractor rejection was more difficult in the absence of the salience of a familiar colored target. It should also be noted that this difficulty was unaffected by practice.

\section{Discussion}

The basic RT data replicate Rappaport et al. (2013); search was more efficient for a target carrying a familiar color than for a target with an unfamiliar color. When the target had an unfamiliar color, search efficiency was in the range frequently found in conjunction search ( $23 \mathrm{~ms} /$ item). This was nearly 


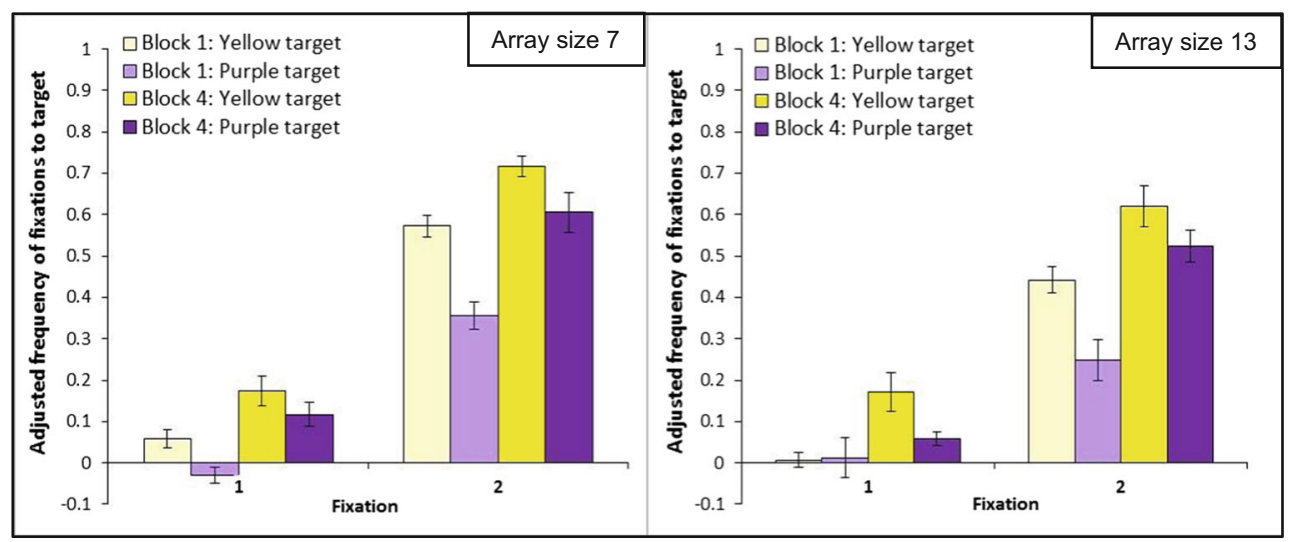

Fig. 4 Mean adjusted frequencies ( \pm 1 standard error) of first and second fixations to the target in Experiment 1, split by block and array size. Data are adjusted for chance

halved when the target had its familiar color $(15 \mathrm{~ms} /$ item $)$. This basic result is consistent with target selection being much less constrained by the demands of binding color and form when the target carries its familiar color. The pattern was present across all the blocks of trials (and, indeed was largest for block 1); thus the advantage for correctly colored objects does not reflect differential learning within the experiment.

The eye movement data reinforce the results from the RT analysis. More first fixations were directed to targets in familiar relative to unfamiliar colors, and this held across different display sizes. Following Rappaport et al. (2013), these findings suggest efficient activation of the color normally associated with the target shape which may be reinforced by a slower activation of top-down guidance (affecting second fixations most). In addition, our analysis of fixations to distractors (footnote 2) indicated that the bias of first fixations to yellow relative to purple distractors was robust across trial blocks. This again indicates that there was some influence of top-down guidance based on prior knowledge of the target's usual color (yellow), which also developed over time.

The fixation duration data indicated that the time taken for initial eye movements to be redirected from a distractor to a

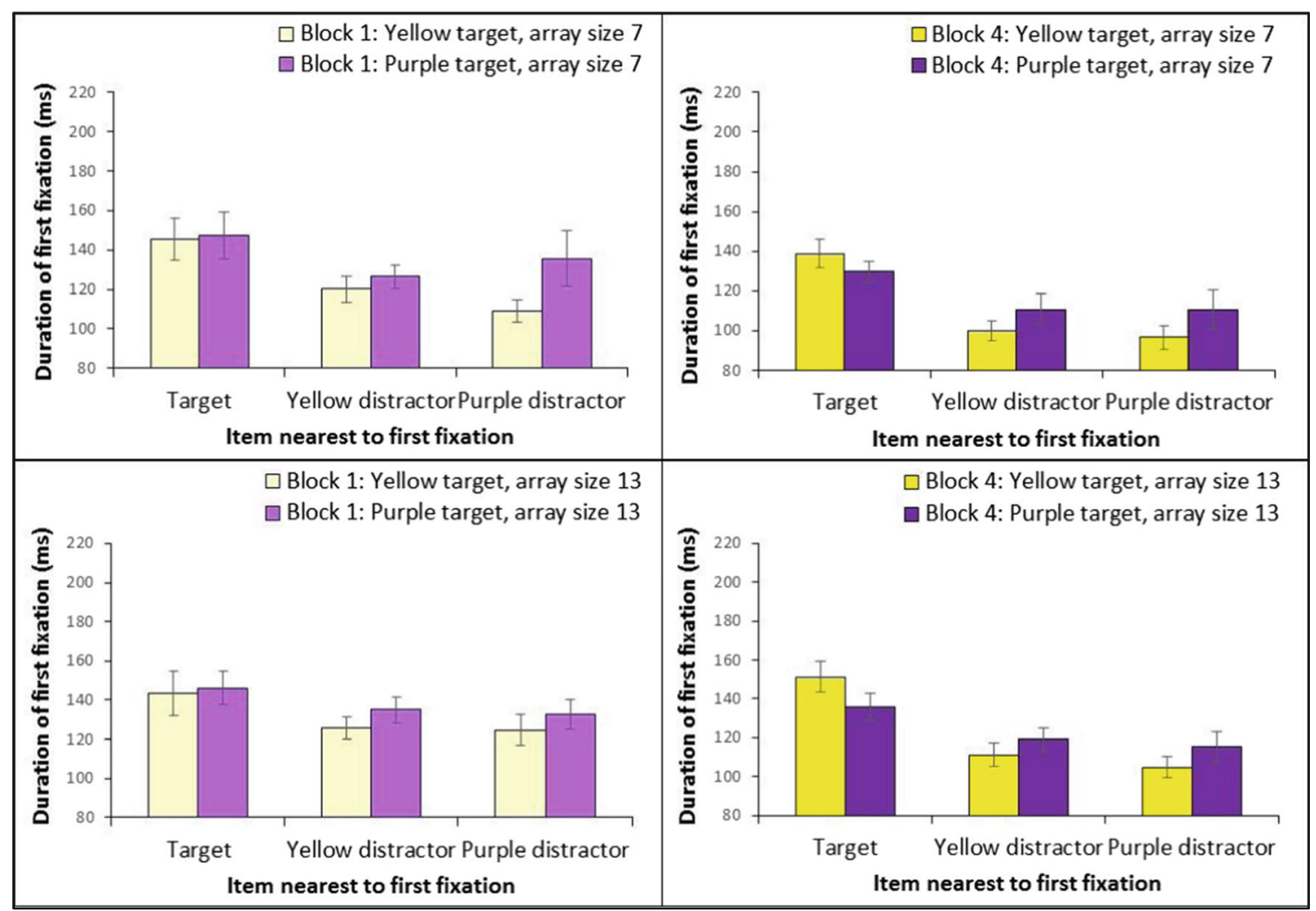

Fig. 5 Mean durations ( \pm 1 standard error) of first fixations in Experiment 1 , split by item nearest first fixation, block, and array size 
target was longer when the target was in an unfamiliar color (purple) relative to when the target was colored correctly (yellow). This is consistent with the familiar target color helping to guide attention across a trial, even when the first fixation went to a distractor.

The findings in Experiment 1 indicate effects of both bottom-up and top-down guidance of attention to targets in familiar color. The fact that the advantage to targets in familiar colors was reduced by practice is consistent with a bottom-up bias in attention to a target in its familiar color, which operates even at the early stages of the experiment. However, there was also evidence for a top-down effect. For example, the bias for first fixations to yellow rather than purple distractors did not decrease across trial blocks, suggesting an increased top-down weighting to the familiar target color over trials. In addition to this the repeated exposure of participants to the target in an unfamiliar color over time improved recognition. The contrast with the consistent bias of fixations to yellow distractors suggests that there may be tuning of both a template of the target in long-term memory (tuning search to the familiar color) and the construction of a template for the unfamiliar target, operating in conjunction across trials. In Experiment 2, we tested whether explicitly cueing participants to expect the following target to carry either a familiar or unfamiliar color can override the early bias towards items with the color typically associated with the target. We also investigated whether cueing may have a similar effect to practice on behavior, comparing performance pre- and post-blocks of trials where cueing was employed.

\section{Experiment 2: Cueing the target color}

In Experiment 2 we explicitly manipulated top-down expectancies by cueing the likely target color at the start of each trial. Cueing the likely features of the target has previously been shown to direct search to items matching the cue, particularly when the target's color is pre-specified (Anderson, Heinke, \& Humphreys, 2013), with valid cues facilitating search and invalid cues slowing search. Here we introduced a pre-trial cue to the target's color that was $80 \%$ valid, a level that has previously been shown to effectively modulate search behavior (Anderson et al., 2013; Meeter \& Theeuwes, 2006; Müller, Heller, \& Ziegler, 1995). Participants were cued either with the familiar or the unfamiliar color for the target (corn), contrasting with the study of Rappaport et al. (2013, Experiment 3), when expectancies were only set for the unfamiliar color of the target. This provided a novel test of whether there was differential top-down cueing for familiar colors of objects. For example, does holding an expectancy for the familiar target color produce greater disruption of search for a target carrying an unfamiliar color than vice versa. In addition, we assessed if there was disruption of search from cueing the unfamiliar target color when the target carried its familiar color (i.e., on invalid trials). If there is facilitated bottom-up processing of targets in their correct colors (see Rappaport et al., 2013), then search for such targets should be minimally disrupted by cueing the unfamiliar color. Furthermore, we were interested in whether pre-trial cueing would have a similar effect on behavior as that exhibited by practice in Experiment 1, facilitating search for targets carrying an unfamiliar color.

In the study, blocks of cued trials were preceded and followed by trial blocks where the target color was not cued. The initial trial block provided a within-subjects baseline measure of the advantage for targets in their correct color. The final trial block provided a test of performance after participants had been encouraged (during the cue blocks) to form expectancies of targets sometimes in their unfamiliar color.

\section{Method}

The methodology closely matched that of Experiment 1 . Differences are outlined below.

\section{Participants}

Twenty-four undergraduates from Oxford Brookes University, seven male, aged 18-46 years (mean 22.5 years), took part for course credits. Two participants were removed due to problems with eye-tracking calibration.

Design

This was a three-factor between-participants design; however, these factors differed depending on the trial block and whether cues were presented prior to each trial. The factors for uncued neutral trials (blocks 1 and 4$)$ were: block $(1$ or 4$) \times$ target color (yellow or purple) $\times$ array size (seven or 13). The factors for cued trials (blocks 2 to 3 ) were: cue validity (valid or invalid) $\times$ target color (yellow or purple) $\times$ array size (seven or 13).

\section{Stimuli}

The display matched that of Experiment 1. However, during cued trials, "NEUTRAL" cues were replaced by either "YELLOW" (20 mm, $1.76^{\circ}$, long, and $4 \mathrm{~mm}, .35^{\circ}$, tall) or "PURPLE" (22 mm, 1.94\%, long, and $4 \mathrm{~mm}, 35^{\circ}$, tall) words.

\section{Procedure}

Trials were identical to those in Experiment 1; however, in blocks 2 and 3 the word prior to the display matched the color of the target on $80 \%$ of trials. Participants were informed of 
this relationship and examples were included in the practice trials at the beginning of the experiment. Despite this instruction, it was stressed that the color of the target remained irrelevant to the task, which was to find the target, corn, irrespective of its color.

\section{Neutral trials: RTs (blocks 1 and 4)}

Adjusted median RTs for correct neutral trials, split by target color and array size, were calculated for each participant, with the data split by block (either block 1 or block 4). Adjusted RTs were calculated by dividing RTs by the proportion of correct trials. Group means are shown in Fig. 6.

There were main effects of block $(\mathrm{F}(1,21)=41.997, \mathrm{p}<$ .001 , partial $\left.\eta^{2}=.667\right)$, target color $(\mathrm{F}(1,21)=16.499, \mathrm{p}<$ .001 , partial $\left.\eta^{2}=.44\right)$, and array size $(\mathrm{F}(1,21)=85.904, \mathrm{p}<$ .001 , partial $\left.\eta^{2}=.804\right)$. Search in block 4 was quicker than in block 1 (646 ms vs. $791 \mathrm{~ms}$ ) while search for a yellow target was quicker than for a purple target (688 ms vs. $749 \mathrm{~ms}$ ), and quicker on seven-item versus 13-item displays (666 ms vs. $771 \mathrm{~ms})$. There were also two-way interactions: block $\times$ array size $\left(\mathrm{F}(1,21)=17.097, \mathrm{p}<.001\right.$, partial $\left.\eta^{2}=.449\right)$, and target color $\times$ array size, $F(1,21)=5.942, p=.024$, partial $\left.\eta^{2}=.221\right)$. Search was more efficient in block 4 (difference across array size of $68 \mathrm{~ms}, \mathrm{p}<.001$, slope of $11 \mathrm{~ms} /$ item) compared to block 1 (difference across array size of $141 \mathrm{~ms}, \mathrm{p}<.001$, slope of $24 \mathrm{~ms} /$ item). Similarly, across the trial blocks, search efficiency for yellow targets was reduced relative to search efficiency purple targets (yellow target, a difference across array size of $81 \mathrm{~ms}, \mathrm{p}<.001$, slope of $13 \mathrm{~ms} /$ item; purple target, a difference across array size of $128 \mathrm{~ms}, \mathrm{p}<.001$, slope of $21 \mathrm{~ms} /$ item).

\section{Neutral trials: First and second fixations}

As in Experiment 1, we measured where the first two fixations were directed during search, along with the duration of first

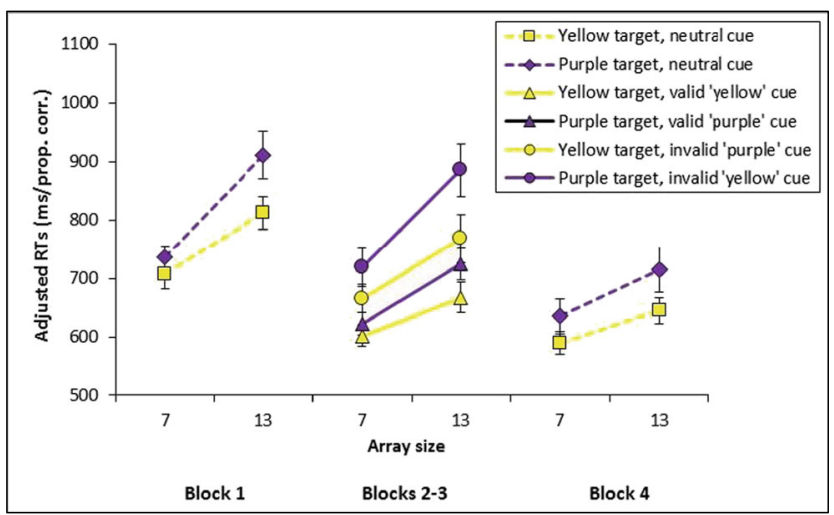

Fig. 6 Mean adjusted RTs ( \pm 1 standard error) in Experiment 2 , split by target color and array size, as well as block for neutral trials in blocks 1 and 4 , and cue validity for trials in blocks $2-3$. Adjusted RTs were calculated by dividing RTs with the relevant accuracy measure fixations. First, we calculated the frequencies with which the first and second fixations were made to each item type. Frequencies of target-fixations are shown in Fig. 7, with data adjusted for chance as previously.

\section{Neutral trials: Fixations to the target}

Data from each fixation were analyzed separately.

First fixations to the target There was a main effect of block $\left(\mathrm{F}(1,21)=47.119, \mathrm{p}<.001\right.$, partial $\left.\eta^{2}=.692\right)$. There were more first fixations to the target in block 4 compared to block 1 (.041 vs. .155). There was also a block $\times$ target color interaction $\left(\mathrm{F}(1,21)=10.578, \mathrm{p}=.004\right.$, partial $\left.\eta^{2}=.335\right)$. There was a larger increase in fixations to yellow targets across blocks than for purple targets (differences of .15, $\mathrm{p}<.001$, and $.078, \mathrm{p}<.001$ ), so that in block 4 there were more first fixations to familiar than unfamiliar targets (a difference of $.058, \mathrm{p}=.049$ ). The same did not hold in block 1 (a difference in first fixations to yellow and purple targets of .014, $\mathrm{p}=.415$ ).

Second fixations to the target There were main effects of block $\left(\mathrm{F}(1,21)=112.36, \mathrm{p}<.001\right.$, partial $\left.\eta^{2}=.843\right)$, array size $\left(\mathrm{F}(1,21)=39.592, \mathrm{p}<.001\right.$, partial $\left.\eta^{2}=.653\right)$, and target color $\left(\mathrm{F}(1,21)=8.359, \mathrm{p}=.009\right.$, partial $\left.\eta^{2}=.285\right)$. There were more second fixations to the target on block 4 compared to block 1 (.623 vs. .403), on displays with smaller compared to larger array sizes (.565 vs. .46), and more second fixations to familiar compared to unfamiliar targets (.54 vs. .485). A block $\times$ target color interaction was also evident $(\mathrm{F}(1,21)=7.602, \mathrm{p}$ $=.012$, partial $\left.\eta^{2}=.266\right)$. The increase in second fixations to targets from block 1 to block 4 was larger for yellow compared to purple targets (differences of .262, p $<.001$, and .177 , $\mathrm{p}<.001$, respectively), so that more second fixations were to familiar than unfamiliar targets in block 4 (a difference of .098, $\mathrm{p}<.001$ ) but not in block 1 (a difference of $.013, \mathrm{p}=.656)$.

\section{Neutral trials: Duration of first fixations}

As in Experiment 1, the durations of first fixations were calculated with the data split by item nearest first fixation, block, array, and target color. Group means are shown in Fig. 8.

There was a main effect of item nearest fixation $(\mathrm{F}(2,42)=$ $32.251, \mathrm{p}<.001$, partial $\left.\eta^{2}=.606\right)$. First fixations to targets were longer than first fixations to either yellow or purple distractors (differences of $52 \mathrm{~ms}, \mathrm{p}<.001$, and $55 \mathrm{~ms}, \mathrm{p}<$ .001 , respectively). The difference in duration between fixations to either type of distractor did not approach significance (a difference of $3 \mathrm{~ms}, \mathrm{p}=.885$ ).

The item nearest fixation factor interacted with both block (block $\times$ item nearest fixation: $F(1.324,27.804)=9.607, p=$ .002 , partial $\eta^{2}=.314$ ) and array size (array size $\times$ item nearest 


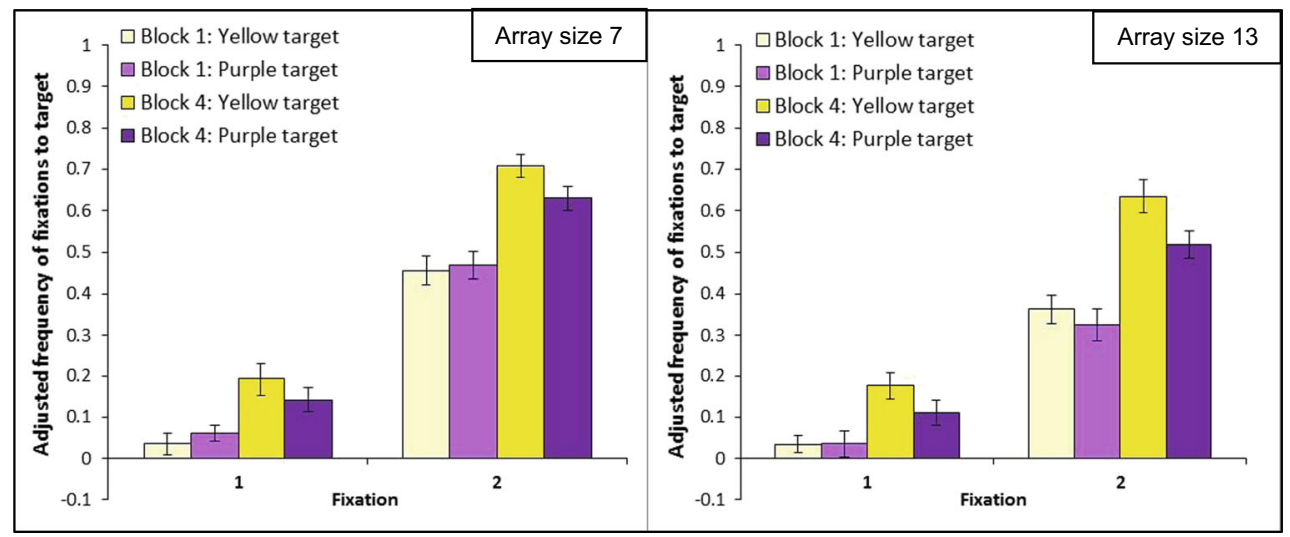

Fig. 7 Mean adjusted frequencies ( \pm 1 standard error) of first and second fixations to the target on neutral trials in Experiment 2, split by block and array size. Data are adjusted for chance

fixation: $\mathrm{F}(1.426,29.946)=7.354, \mathrm{p}=.006$, partial $\left.\eta^{2}=.259\right)$. Unpacking the block $\times$ item nearest fixation interaction, durations of target-fixations marginally increased across block (a difference of $15 \mathrm{~ms}, \mathrm{p}=.062$ ), whilst duration to distractors decreased with practice (fixations to yellow distractors, a difference across blocks of $12 \mathrm{~ms}, \mathrm{p}=.001$; fixations to purple distractors, a difference across blocks of $12 \mathrm{~ms}, \mathrm{p}=.008$ ). The array $\times$ item nearest fixation interaction was driven by the durations of fixations to yellow and purple distractors increasing with array size (differences of $10 \mathrm{~ms}, \mathrm{p}<.001$, and $12 \mathrm{~ms}$, $\mathrm{p}<.001$, respectively). A similar-sized decrease for target fixations across array size did not reach significance (a difference of $10 \mathrm{~ms}, \mathrm{p}=.156$ ). The interaction between item nearest fixation and target color did not approach significance $\left(\mathrm{F}(1.098,23.053)=1.577, \mathrm{p}=.218\right.$, partial $\left.\eta^{2}=.070\right)$.

The findings indicate that, with practice, distractor rejection was facilitated whilst the greater uncertainty induced at larger displays sizes prolonged fixations specifically to distractors.

\section{Cued trials: RTs}

Adjusted median RTs on correct cued trials, split by target color, and array size were calculated for each participant, with

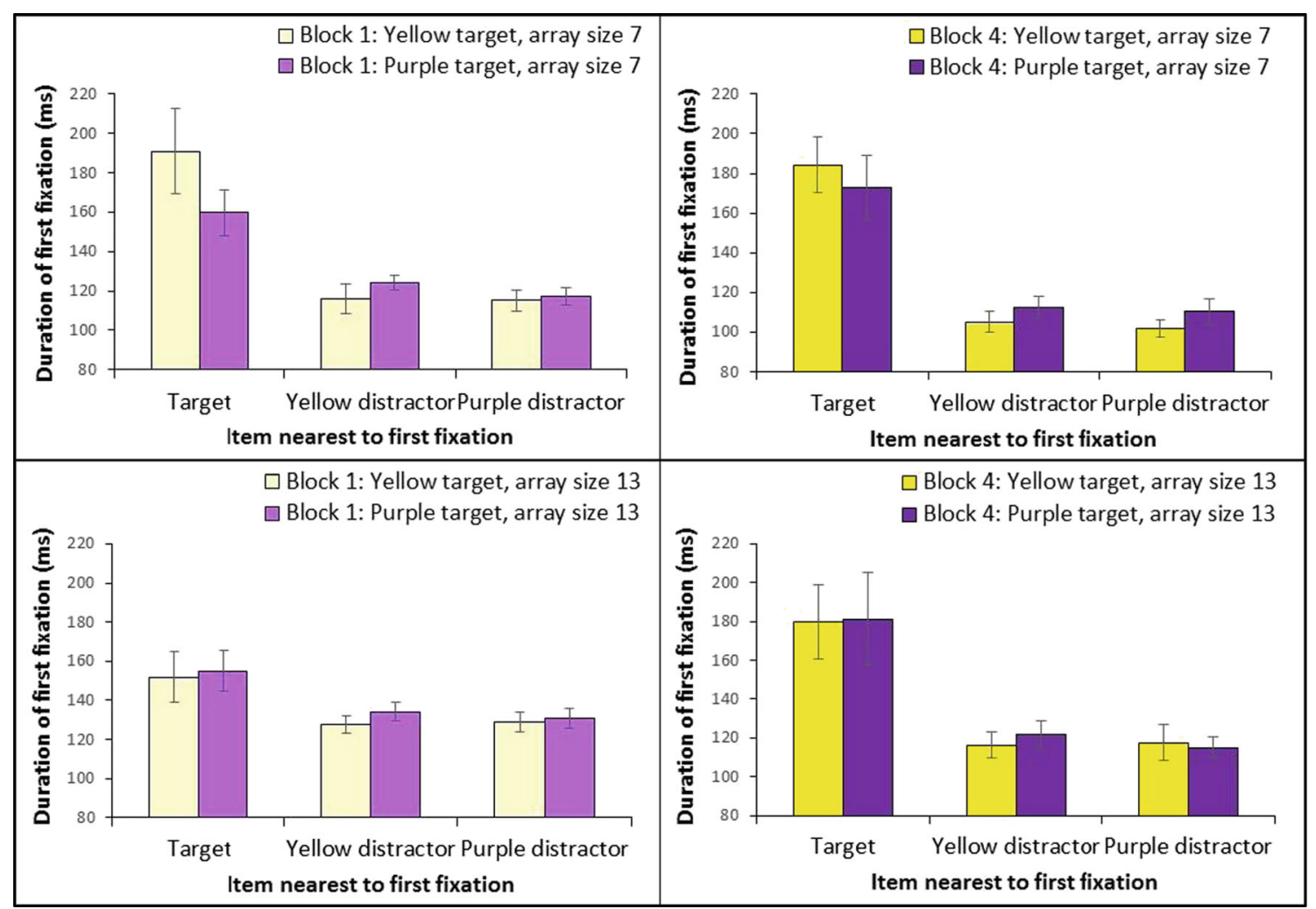

Fig. 8 Mean durations ( \pm 1 standard error) of first fixations on neutral trials in Experiment 2, split by item nearest fixation, block, and array size 
the data split by cue validity (valid cues matched the target, invalid cues did not). Group means are shown in Fig. 6.

Analyzing RTs on cued trials (blocks 2-3), there were main effects of array size $(\mathrm{F}(1,21)=49.307, \mathrm{p}<$ .001 , partial $\left.\eta^{2}=.701\right)$, cue validity $(\mathrm{F}(1,21)=28.067$, $\mathrm{p}<.001$, partial $\left.\eta^{2}=.572\right)$, and target color $(\mathrm{F}(1,21)=$ $8.157, \mathrm{p}=.009$, partial $\eta^{2}=.28$ ). Search was quicker on smaller displays (seven-item arrays, $655 \mathrm{~ms}$ vs. 13item displays, $759 \mathrm{~ms}$ ), on valid compared to invalid trials (662 ms vs. $759 \mathrm{~ms}$ ), and for yellow compared with purple targets $(684 \mathrm{~ms}$ vs. $737 \mathrm{~ms})$.

There were also two interactions: cue validity $\times$ target color $\left(\mathrm{F}(1,21)=6.592, \mathrm{p}=.018\right.$, partial $\left.\eta^{2}=.239\right)$ and target color $\times$ array size interactions $\left(\mathrm{F}(1,21)=6.558, \mathrm{p}=.018\right.$, partial $\eta^{2}=$ .238). The cue validity $\times$ target color interaction indicated a larger validity effect for purple compared with yellow targets (purple targets, a difference between valid and invalid trials of $128 \mathrm{~ms}, \mathrm{p}<.001$; yellow targets, a difference between valid and invalid trials of $65 \mathrm{~ms}, \mathrm{p}=.005$ ). On valid cues there was only a borderline significant advantage when searching for yellow compared to purple targets (a difference of $22 \mathrm{~ms}, \mathrm{p}=.083$ ). On invalid trials, however, search for yellow targets was quicker (a difference between yellow and purple targets of $85 \mathrm{~ms}, \mathrm{p}=.008$ ). The target color $\times$ array size interaction arose because of improved search efficiency for yellow targets. There was a smaller effect of array size on search for yellow targets (a difference of $88 \mathrm{~ms}, \mathrm{p}<.001$; slope $15 \mathrm{~ms} /$ item) compared with search for purple targets (a difference of $135 \mathrm{~ms}, \mathrm{p}<.001$, slope $22 \mathrm{~ms} /$ item).

\section{Cued trials: First and second fixations}

Group means of frequencies of fixations to targets are shown in Fig. 9. As before, data were adjusted for chance, and first and second fixation data were analyzed separately.

\section{Cued trials: Fixations to the target}

First fixations to the target There were no significant main effects or interactions (maximum $\mathrm{F}$ value of 3.029).

Second fixations to the target There were main effects of array size $\left(\mathrm{F}(1,21)=16.05, \mathrm{p}=.001\right.$, partial $\left.\eta^{2}=.433\right)$, cue validity $(\mathrm{F}(1,21)=11.578), \mathrm{p}=.003$, partial $\eta^{2}=$ $.355)$, and target color $(\mathrm{F}(1,21)=8.552, \mathrm{p}=.008$, partial $\eta^{2}=.289$ ). There were more second fixations to the target on small than large displays (seven-item displays, .596 , vs. 13-item displays, .494), and on valid compared to invalid trials (.592 vs. .498). There were also more fixations to yellow versus purple targets (.588 vs. .502). There were no reliable interactions.

\section{Cued trials: Duration of first fixations on cued trials}

Group means of the duration of first fixations are shown in Fig. 10, split by item nearest fixation, array size, cue validity, and target color. There was a robust main effect of item fixated $\left(\mathrm{F}(1.216,25.537)=66.263, \mathrm{p}<.001\right.$, partial $\left.\eta^{2}=.759\right)$. Initial fixations to the target were longer than fixations to both yellow and purple distractors (differences of $52 \mathrm{~ms}, \mathrm{p}<.001$, and $50 \mathrm{~ms}, \mathrm{p}<.001$, respectively). The difference between durations of fixations to the two types of distractor did not approach significance (a difference of $2 \mathrm{~ms}^{3}$ ).

There was also a target color $\times$ item nearest fixation interaction $\left(\mathrm{F}(1.29,27.094)=6.855, \mathrm{p}=.009\right.$, partial $\left.\eta^{2}=.246\right)$. First fixations to yellow targets were longer than to purple targets (a difference $21 \mathrm{~ms}, \mathrm{p}=.016$ ), whilst fixations to yellow distractors were longer on purple target displays than when the target was yellow (a difference of $11 \mathrm{~ms}, \mathrm{p}=$ $.005)$. There was no effect of target color on the duration of fixations to purple distractors (a difference of $2 \mathrm{~ms}, \mathrm{p}=.661$ ).

\section{Discussion}

We first discuss neutral trials before the trial blocks where targets were cued. Search RTs for neutral trials in Experiment 2 largely matched that of Experiment 1 . Search was quicker and search more efficient for yellow compared to purple targets; however, there were contrasting patterns when comparing search efficiency across blocks. When no cues were presented across the experiment (Experiment 1), search for yellow targets remained more efficient after practice. In contrast, when blocks of uncued trials were interspaced by trials where target color was cued (Experiment 2), search efficiency for yellow and purple targets was matched in the fourth trial block, although search speed overall still favored yellow targets.

The eye movement data indicate that practice increased the proportion of first fixations to target in familiar (yellow) relative to unfamiliar colors (purple) across blocks. There was a similar trend in Experiment 1, though it was not reliable. In block 1, though, the advantage for targets in familiar colors was not reliable here. Although there was a larger behavioral gain on search for purple targets, first fixations to familiar targets also benefitted from practice. There were also gains in second fixations to targets with practice, and again this increase was more marked for targets in familiar relative to unfamiliar colors. The data indicate stronger tuning across trials of the stored template of the target in its familiar color, relative to the newly established template for an unfamiliar target color.

\footnotetext{
${ }^{3}$ The probability associated with this post hoc comparison was $\mathrm{p}=1$; however, this value is an artefact of the Bonferroni adjustments made by SPSS software and the value is therefore omitted.
} 


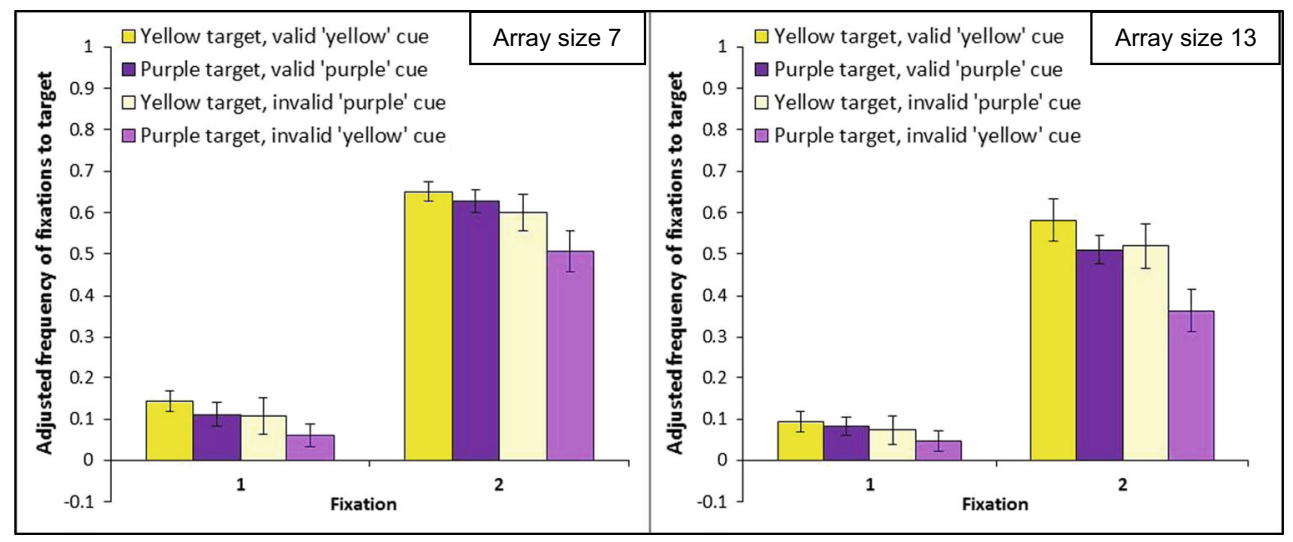

Fig. 9 Mean adjusted frequencies ( \pm 1 standard error) of first and second fixations to items on cued trials in Experiment 2, split by item fixated (target, yellow distractors, purple distractors), cue validity, and array size. Data are adjusted for chance

Turning to the cued trials in Experiment 2, the data demonstrate that cueing the target's color (in blocks 2 and 3) was effective in modulating performance. Search was more efficient on valid relative to invalid trials. Cueing also interacted with target color familiarity. When the cue matched the target, differences between targets in familiar and unfamiliar colors were modest, whereas strong differences emerged on invalid trials. That is, the cost of an incorrect expectancy for a target in an unfamiliar color was greater than the cost when the target appeared in its familiar color. Having a target in its familiar color reduced the effect of invalid cueing. This result is reminiscent of an attentional disengagement effect (cf. Posner, 1980), but in the semantic rather than spatial domain.

Whether the cues did or did not match the target color produced little or no gain on whether first or second fixations were to the familiar target, when compared with when the target was in its incorrect color. Indeed, following a purple color cue, fixations were no more likely to go to the validly cued unfamiliar purple target than to the familiar yellow target when the cue was invalid (see Fig. 9). The findings suggest that, in addition to any cueing of expectations to a particular color, there remained increased bottom-up salience of familiar targets (e.g., Rappaport et al., 2013).

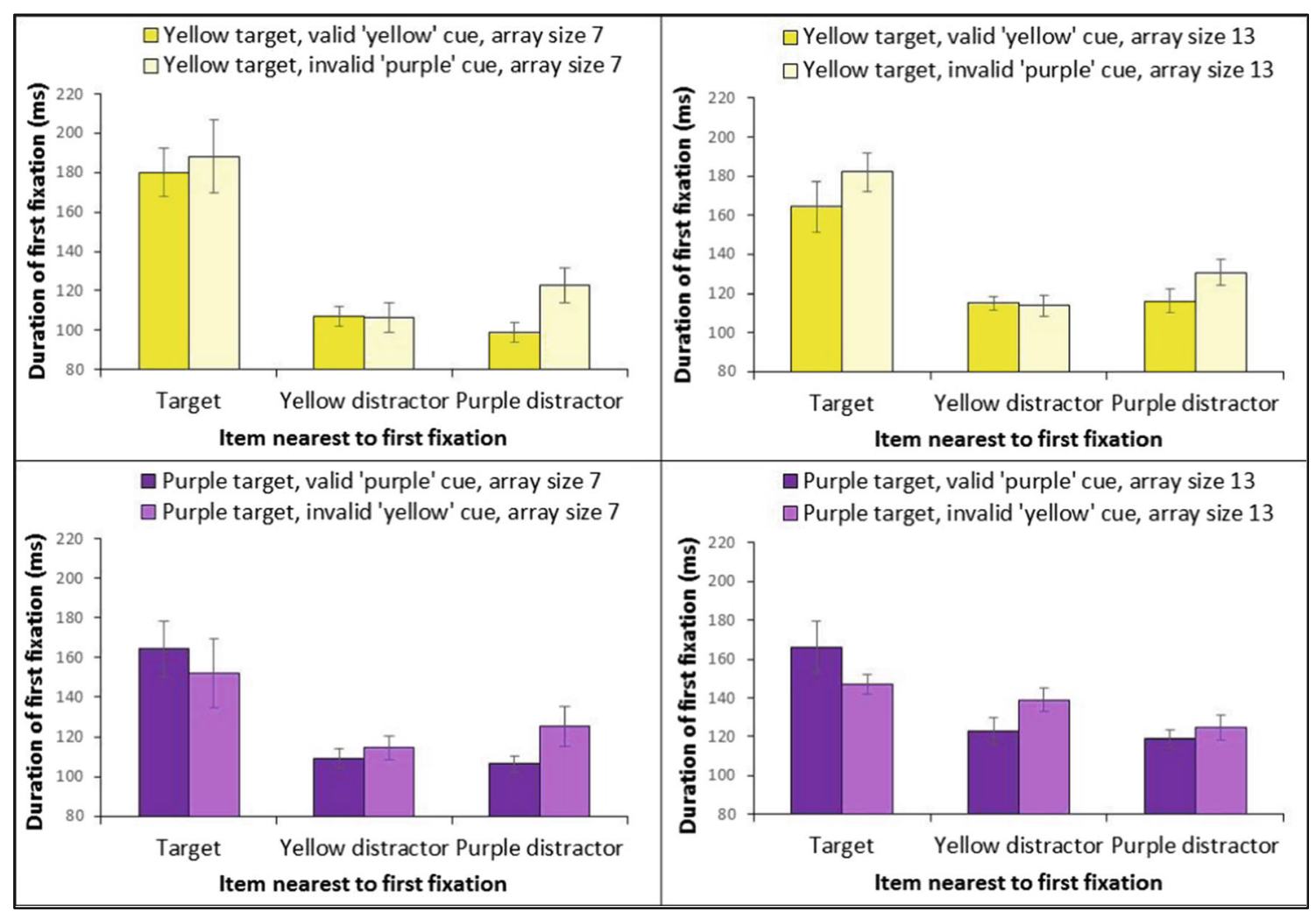

Fig. 10 Mean durations ( \pm 1 standard error) of first fixations on cued trials in Experiment 2 , split by item nearest first fixation, cue validity, and array size 
In Experiment 3, we assessed the generality of these results by probing performance with different items where we reversed the familiar and unfamiliar colors.

\section{Experiment 3: Cued search for aubergine targets}

It is possible that the difference in search for familiar and unfamiliar targets in Experiments 1 and 2 could be attributed not to the familiarity of the association between the target and its color but to the colors themselves. Search for a yellow item may be quicker and more efficient than for a purple item, irrespective of the associations of the color with the target shape. To test this proposal, Experiment 3 replicated Experiment 2 but switched the target-distractor identity. In this case, search was for an aubergine target with corn distractors. The familiar target color was therefore purple, whilst the unfamiliar target color was yellow.

\section{Method}

Experiment 3 replicated Experiment 2 with the following amendments.

\section{Participants}

Twenty-two undergraduates from Oxford Brookes University, five male, aged 18-36 years (mean 21.6 years), took part for course credits.

\section{Procedure}

Target and distractor identities were switched (see Fig. 1), so that participants searched for an aubergine amongst corn distractors.

\section{Results}

\section{Neutral trials: RTs}

Adjusted median RTs on correct trials for each participant within each condition were calculated. Group means from neutral, alongside cued trials are shown in Fig. 11.

There were main effects of block $(F(1,21)=65.442, p<.001$, partial $\left.\eta^{2}=.757\right)$, array size $(\mathrm{F}(1,21)=26.094, \mathrm{p}<.001$, partial $\left.\eta^{2}=.554\right)$, and target color $(\mathrm{F}(1,21)=20.092, \mathrm{p}<.001$, partial $\left.\eta^{2}=.554\right)$. Search was quicker in block 4 compared to block 1 (630 ms vs. $768 \mathrm{~ms}$ ) and on seven-item displays compared to 13-item displays (673 ms vs. $725 \mathrm{~ms}$ ). Furthermore, search for purple targets was quicker than search for yellow targets $(659 \mathrm{~ms}$ vs. $739 \mathrm{~ms}$ ). There were several two-way interactions (block $\times$ array size, $\mathrm{F}(1,21)=14.278, \mathrm{p}=.001$, partial $\eta^{2}=.405$; block $\times$ target color, $\mathrm{F}(1,21)=4.389, \mathrm{p}=.048$, partial $\eta^{2}=.173$; array size $\times$ target color, $\mathrm{F}(1,21)=5.946, \mathrm{p}=.024$, partial $\left.\eta^{2}=.221\right)$ as well as a three-way interaction (block $\times$ array size $\times$ target color, $\mathrm{F}(1,21)=8.64, \mathrm{p}=.008$, partial $\left.\eta^{2}=.291\right)$.

To understand the three-way interactions, the data were split by block and re-analyzed.

Block 1 There were main effects of array size $(\mathrm{F}(1,21)=$ $35.042, \mathrm{p}<.001$, partial $\left.\eta^{2}=.625\right)$ and target color $(\mathrm{F}(1,21)$ $=17.133, \mathrm{p}<.001$, partial $\left.\eta^{2}=.449\right)$. Search was quicker on seven-item compared to 13 -item displays (726 ms vs. $810 \mathrm{~ms}$ ). Search was quicker for purple than yellow targets ( $717 \mathrm{~ms}$ vs. $818 \mathrm{~ms}$ ). There was also an array size $\times$ target color interaction $\left(F(1,21)=8.961, p=.007\right.$, partial $\left.\eta^{2}=.299\right)$. Search for purple targets was more efficient than search for yellow targets (differences across array size of $36 \mathrm{~ms}, \mathrm{p}=.021$, and $133 \mathrm{~ms}, \mathrm{p}<$ .001 , and slopes of $6 \mathrm{~ms} /$ item vs. $22 \mathrm{~ms} /$ item, respectively).

Block 4 There was a main effect of target color $(\mathrm{F}(1,21)=$ $14.634, p=.001$, partial $\left.\eta^{2}=.441\right)$. Search was quicker for purple compared to yellow targets (600 ms vs. $660 \mathrm{~ms})$. The main effect of array size did not reach significance $(\mathrm{F}(1,21)=$ $2.373, \mathrm{p}=.138$, partial $\left.\eta^{2}=.102\right)$ and the two factors did not interact $(\mathrm{F}<1)$. The search slope for purple targets was $3 \mathrm{~ms} /$ item and for yellow targets was $4 \mathrm{~ms} /$ item.

\section{Neutral trials: First and second fixations}

Eye-tracking data were processed as previously and the item nearest to the first two fixations were assessed. Frequencies were then adjusted for chance. Group means of the frequency of fixations to targets are shown in Fig. 12.

\section{Neutral trials: Target-fixations}

First fixations to the target There were main effects of block $\left(\mathrm{F}(1,21)=18.586, \mathrm{p}<.001\right.$, partial $\left.\eta^{2}=.47\right)$ and target color

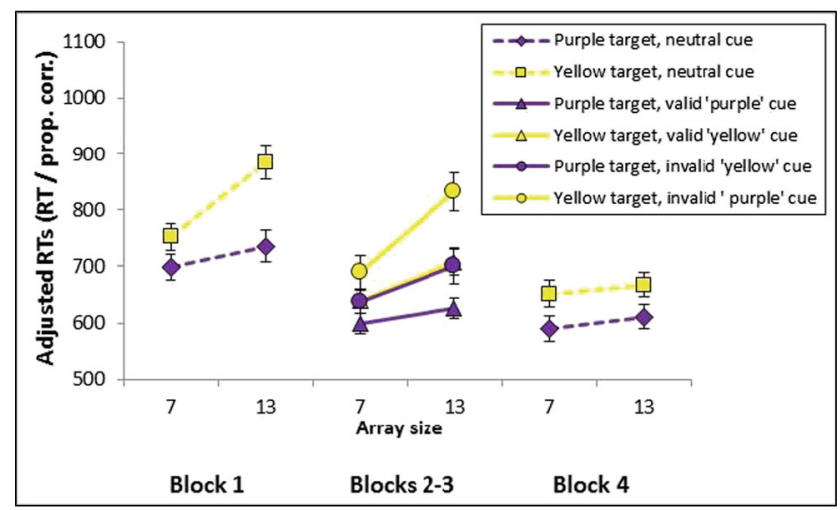

Fig. 11 Mean adjusted response times (RTs) ( \pm 1 standard error) in Experiment 3, split by target color and array size, as well as by block for trials in blocks 1 and 4, and cue validity for trials in blocks 2-3. Adjusted RTs were calculated by dividing RTs by the relevant accuracy measure 


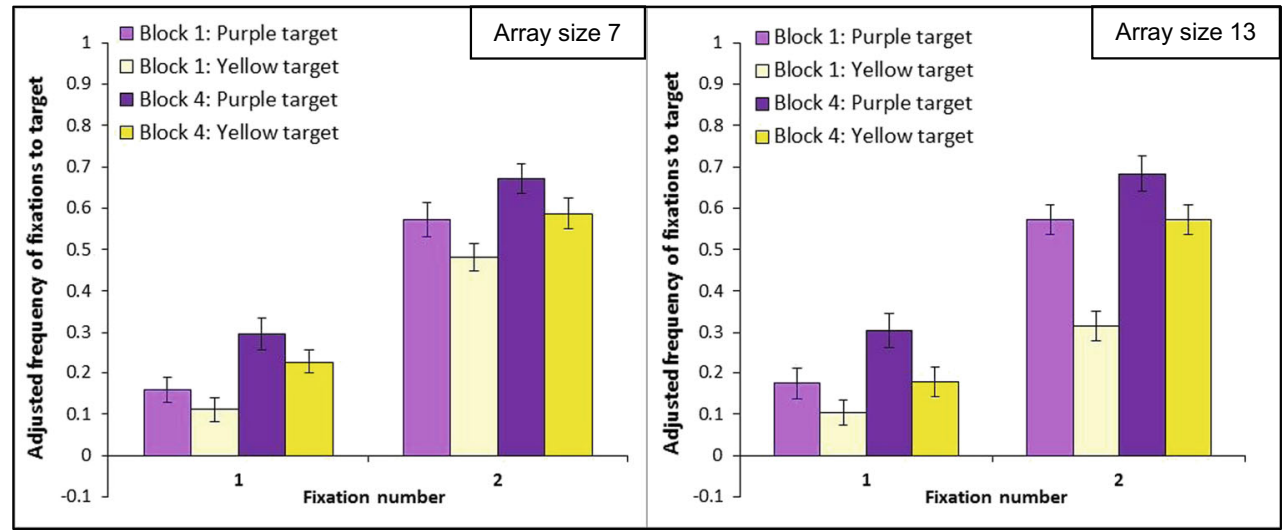

Fig. 12 Mean adjusted frequencies ( \pm 1 standard error) of fixations to targets on neutral trials in Experiment 3, split by block, and array size. Data are adjusted for chance

$\left(\mathrm{F}(1,21)=8.937, \mathrm{p}=.007\right.$, partial $\left.\eta^{2}=.299\right)$. There were more target fixations on block 4 compared to block 1 (.252 vs. .137), and when the target was purple compared to yellow (.234 vs. .155). The target familiarity $\times$ block did not reach significance $\left(\mathrm{F}(1,21)=1.413, \mathrm{p}=.248\right.$, partial $\left.\eta^{2}=.064\right)$.

Second fixations to the target There were main effects of target color $\left(\mathrm{F}(1,21)=24.641, \mathrm{p}<.001\right.$, partial $\left.\eta^{2}=.54\right)$, block $\left(\mathrm{F}(1,21)=23.67, \mathrm{p}<.001\right.$, partial $\left.\eta^{2}=.53\right)$, and array size $\left(\mathrm{F}(1,21)=7.129, \mathrm{p}=.014\right.$, partial $\left.\eta^{2}=.253\right)$. More second fixations were to purple targets compared to yellow targets (.625 vs. .477). There were more second fixations to the target on block 4 compared to block 1 (.628 vs. .485), and on smaller displays compared to larger displays (.578 vs. .536).

There were also two two-way interactions: array size $\times$ target color $\left(\mathrm{F}(1,21)=8.707, \mathrm{p}=.008\right.$, partial $\left.\eta^{2}=.293\right)$, and block $\times$ array size $\left(F(1,21)=5.263, p=.032\right.$, partial $\eta^{2}$ $=.2$ ), as well as a higher level interaction (block $\times$ array size $\times$ target color: $\mathrm{F}(1,21)=4.313, \mathrm{p}=.05$, partial $\left.\eta^{2}=.17\right)$. Unpacking the block $\times$ array size $\times$ target color interaction, there were more second fixations to purple targets versus yellow targets on larger displays in both block 1 (a difference of $.258, \mathrm{p}<.001$ ) and block 4 (a difference of $.112, \mathrm{p}=.038$ ), and on smaller displays in block 4 (a difference of .084, $\mathrm{p}=.015$ ). However, on trials with smaller displays in block 1, the bias towards fixating purple targets was only marginal (a difference of $.091, \mathrm{p}=.055$ ).

\section{Neutral trials: Duration of first fixations}

The mean durations of first fixation are shown in Fig. 13. There was a main effect of item nearest first fixation $\left(F(1.522,31.952)=57.965, p<.001\right.$, partial $\left.\eta^{2}=.734\right)$. First fixations to the target were longer than fixations to either type of distractor (first fixation to target vs. purple distractor, a difference of $29 \mathrm{~ms}, \mathrm{p}<.001$; first fixation to target vs. yellow distractor, a difference of $30 \mathrm{~ms}, \mathrm{p}<.001$ ). The difference in fixation durations to either type of distractor was not significant (a difference of $1 \mathrm{~ms}^{4}$ ).

There was also a target color $\times$ item nearest first fixation interaction $\left(\mathrm{F}\left(1.439,30.229, \mathrm{p}=.6178, \mathrm{p}=.011\right.\right.$, partial $\eta^{2}=$ .227). Unpacking this interaction, first fixations to purple distractors were longer when the target was yellow compared to when it was purple (a difference of $11 \mathrm{~ms}, \mathrm{p}<.001$ ). No other comparisons across target color reached significance.

\section{Cued trials (blocks 2 and 3): RTs}

Adjusted median RTs for correct cued trials are shown in Fig. 11.

The analysis indicated main effects of array size $(\mathrm{F}(1,21)=$ 53.872, $\mathrm{p}<.001$, partial $\left.\eta^{2}=.72\right)$, cue validity $(\mathrm{F}(1,21)=$ 42.848, $\mathrm{p}<.001$, partial $\left.\eta^{2}=.671\right)$, and target color $(\mathrm{F}(1,21)$ $=23.859, p<.001$, partial $\left.\eta^{2}=.532\right)$. Search was quicker on: seven-item versus 13 -item displays ( $646 \mathrm{~ms}$ vs. $720 \mathrm{~ms}$ ), valid versus invalid trials ( $643 \mathrm{~ms}$ vs. $724 \mathrm{~ms}$ ), and for purple versus yellow targets (640 ms vs. $726 \mathrm{~ms}$ ). There were also interactions: cue validity $\times$ array size $(\mathrm{F}(1,21)=8.365, \mathrm{p}=.009$, partial $\left.\eta^{2}=.285\right)$, target color $\times$ array size $(\mathrm{F}(1,21)=7.243$, $\mathrm{p}=.014$, partial $\eta^{2}=.256$ ), and cue validity $\times$ target color $\left(\mathrm{F}(1,21)=5.327, \mathrm{p}=.031\right.$, partial $\left.\eta^{2}=.202\right)$.

The cue validity $x$ array size interaction arose because valid cues improved search efficiency (e.g., increased the number of stimuli processed over time) compared to invalid cues, with the cueing effect being stronger at the larger array size (seven-item displays, a validity effect of $54 \mathrm{~ms}, \mathrm{p}=.002 ; 13$-item displays, a validity effect of $107 \mathrm{~ms}, \mathrm{p}<.001)$. Search slopes were almost twice as steep on invalid compared to valid trials (17 ms/item vs. $8 \mathrm{~ms} /$ item, respectively).

\footnotetext{
${ }^{4}$ The probability associated with this post hoc comparison was $\mathrm{p}=1$; however, this value is an artefact of the Bonferroni adjustments made by SPSS software and so the value was omitted.
} 


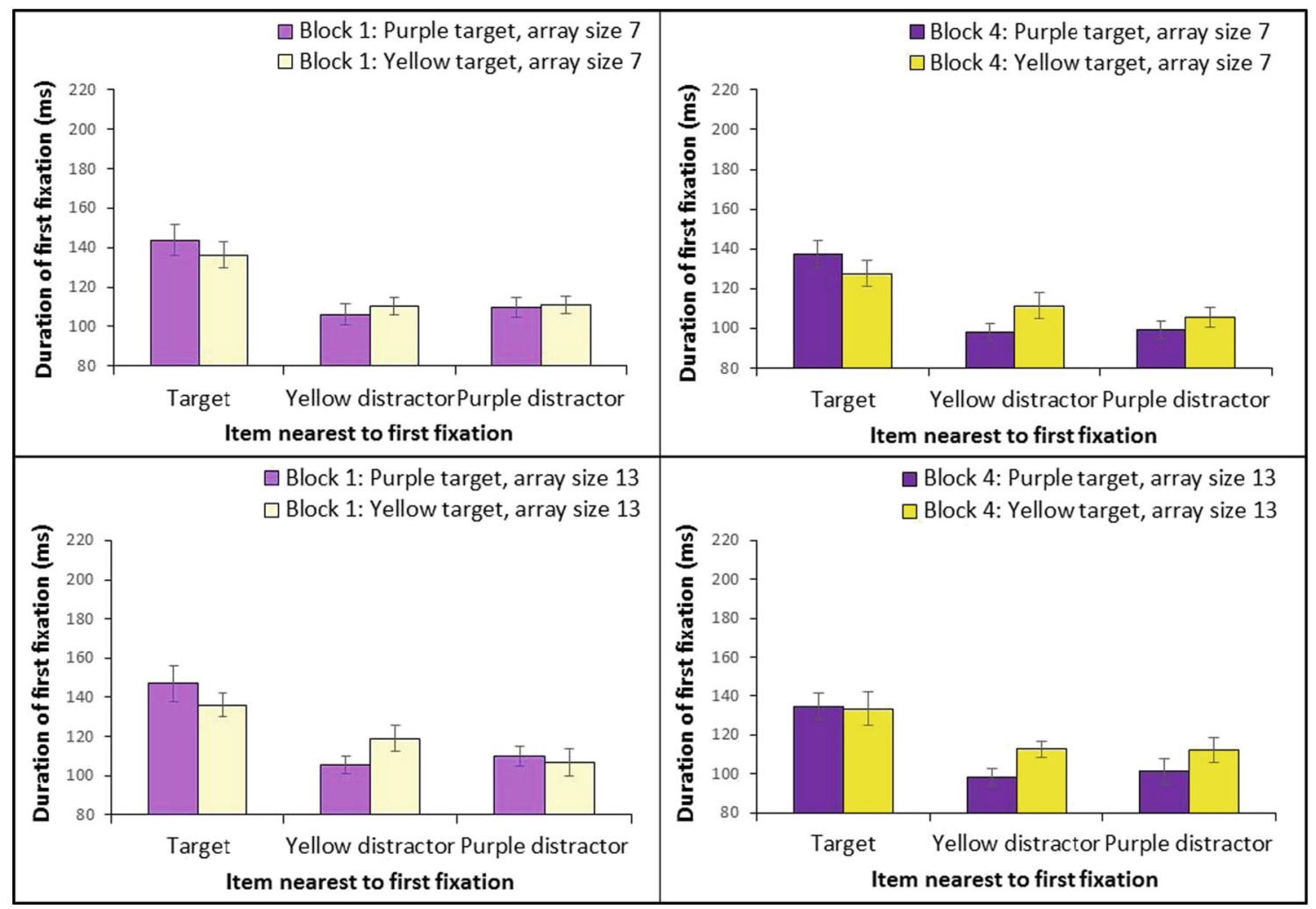

Fig. 13 Mean of mean durations ( \pm 1 standard error) of first fixations on neutral trials in Experiment 3, split by item nearest first fixation, block and array size

The target color $\times$ array size interaction arose because search for purple targets was quicker than for yellow targets, and this advantage increased at larger array sizes (seven-item displays, a difference of $56 \mathrm{~ms}, \mathrm{p}=.001$; 13-item displays, a difference of $114 \mathrm{~ms}, \mathrm{p}<.001)$. Search for purple targets was more efficient than search for yellow targets (search slopes: $9 \mathrm{~ms} /$ item vs. $19 \mathrm{~ms} /$ item).

The target color $\times$ cue validity interaction was driven by a larger effect of cue validity when the target was unfamiliar than when the target was familiar (differences between valid and invalid trials of $106 \mathrm{~ms}, \mathrm{p}<.001$, and $56 \mathrm{~ms}, \mathrm{p}=.002$, respectively). As a consequence, the advantage for familiarly colored targets was reduced on valid trials $(60 \mathrm{~ms}, \mathrm{p}<.001)$ relative to the advantage on invalid trials (a difference of $110 \mathrm{~ms}, \mathrm{p}<.001)$.

\section{Cued trials: First and second fixations}

Group means of target fixations, adjusted for chance, are shown in Fig. 14.

\section{Fixations to targets}

First fixations There were main effects of target color $(\mathrm{F}(1$, $21)=10.351, p=.004$, partial $\left.\eta^{2}=.33\right)$ and cue validity $(F(1$, 21) $=5.453, p=.03$, partial $\eta^{2}=.206$ ). There were more first fixations to purple compared to yellow targets (.22 vs. .198), and more target fixations on valid compared to invalid trials (.238 vs. .179).

T-tests comparing fixations to purple targets on invalid trials and valid yellow targets on valid trials found no difference at either array size (seven-item displays, $\mathrm{t}(21)=.156, \mathrm{p}=.869$, two-tailed; 13 -item displays: $\mathrm{t}(21)=1.283, \mathrm{p}=.213$, two-tailed). Comparing fixations to purple targets on valid trials and yellow targets on invalid trials, there were more fixations to purple targets than yellow but only at array size $13(\mathrm{t}(21)=$ $2.739, \mathrm{p}=.012$, two-tailed; seven-item displays, $\mathrm{t}(21)=$ $.639, \mathrm{p}=.529$, two-tailed).

Second fixations There were main effects of target color $(\mathrm{F}(1$, $21)=29.368, \mathrm{p}<.001$, partial $\left.\eta^{2}=.583\right)$, cue validity $(\mathrm{F}(1,21)$ $=19.324, \mathrm{p}<.001$, partial $\left.\eta^{2}=.479\right)$, and array size $(\mathrm{F}(1,21)=$ $8.377, \mathrm{p}=.009$, partial $\left.\eta^{2}=.285\right)$. There were more second fixations to purple compared to yellow targets (.661 vs. .501), as well as more target fixations on valid compared to invalid trials (.649 vs. .516), and on seven-item compared to 13-item displays (.623 vs. .542).

There was also an array size $\times$ target color interaction $(\mathrm{F}(1$, $21)=17.991, p<.001$, partial $\left.\eta^{2}=.461\right)$. At the larger array size, there was a larger difference between second fixations to purple targets than to yellow targets (a difference of .242, p < 


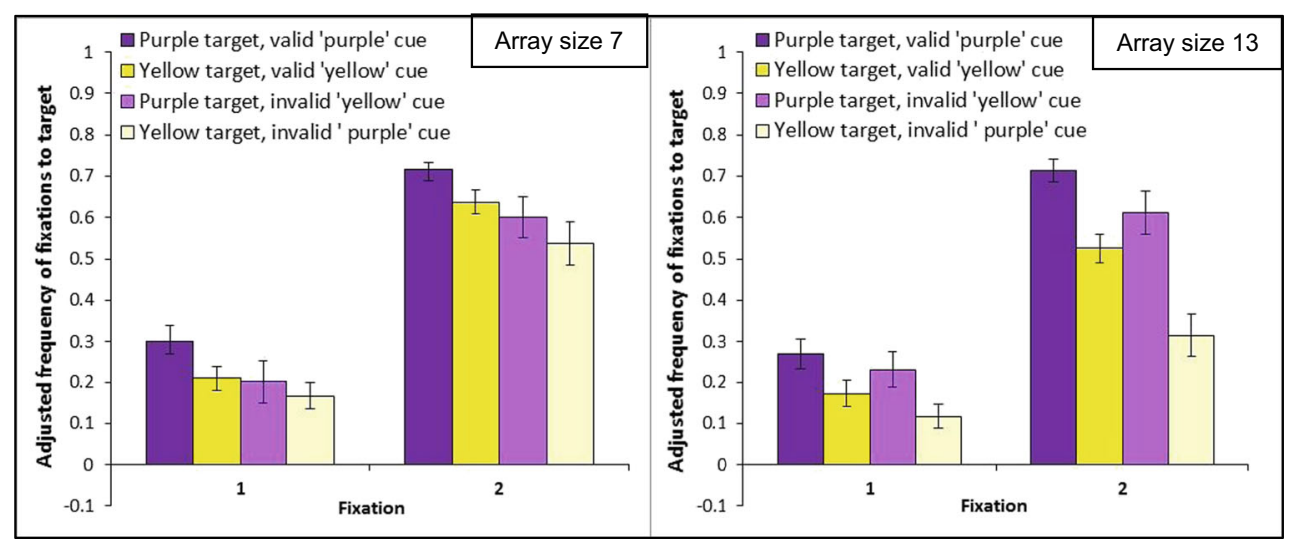

Fig. 14 Mean adjusted frequencies ( \pm 1 standard error) of fixations to targets on cued trials in Experiment 3, split by cue validity, and array size. Data were adjusted for chance

.001) compared to when the display was smaller (a difference of .071, $\mathrm{p}=.056)$.

Comparing whether more second fixations were to purple targets on invalid trials compared to yellow targets on valid trials, again, there were no differences at either array size (seven-item displays, $\mathrm{t}(21)=.816, \mathrm{p}=.424$, two-tailed; 13 item displays, $\mathrm{t}(21)=1.622, \mathrm{p}=.12$, two-tailed). Similar to first fixation data, on invalid trials, there were only more second fixations to purple than yellow targets on larger displays (13-item displays, $\mathrm{t}(21)=5.612, \mathrm{p}<.001$, two-tailed; sevenitem displays, $\mathrm{t}(21)=.985, \mathrm{p}=.336$, two-tailed).

\section{Duration of first fixations}

Figure 15 shows group means. There was a main effect of item fixated $\left(F(2,42)=106.849, p<.001\right.$, partial $\left.\eta^{2}=.836\right)$. First fixations to the target were longer than fixations to either type of distractor (target vs. purple distractors, a difference of $37 \mathrm{~ms}, \mathrm{p}<.001$; target vs. yellow distractors, a difference of $40 \mathrm{~ms}, \mathrm{p}<.001)$. There was no effect of color of distractor fixated on fixation duration (a difference of $3 \mathrm{~ms}, \mathrm{p}=.977$ ).

There was a target color $\times$ item nearest fixation interaction $\left(\mathrm{F}(2,42)=3.382, \mathrm{p}=.043\right.$, partial $\left.\eta^{2}=.139\right)$, which also interacted with cue validity (cue validity $\times$ target color $\times$ item fixated: $F(1.443,30.294)=6.472, p=.009$, partial $\left.\eta^{2}=.236\right)$. On valid trials fixations to targets were longer when the target was yellow (e.g., unfamiliar) compared to when the target was purple (a familiarity difference of $13 \mathrm{~ms}, \mathrm{p}=.007$ ), whilst on invalid trials the duration of first fixations to both colored targets were matched (a difference of $9 \mathrm{~ms}, \mathrm{p}=.437$ ). Furthermore, on valid trials, distractor color did not influence the duration of first fixations (purple distractors, a difference across target color of $4 \mathrm{~ms}, \mathrm{p}=.32$; yellow distractors, a difference across target color of $0 \mathrm{~ms}, \mathrm{p}=.908)$. On invalid trials, however, fixations to purple distractors were longer when the target was yellow (and the invalid cue was "PURPLE") compared to when the target was purple (and the invalid cue was "YELLOW": a difference of $9 \mathrm{~ms}, \mathrm{p}=.045)$.
Fixations to yellow distractors were also longer when the target was purple (and the invalid cue was "YELLOW") compared to when the target was yellow (and the invalid cue was "PURPLE": a difference of $22 \mathrm{~ms}, \mathrm{p}=.004)$. The above findings suggest that when cues matched the target (on valid trials), initial fixations to the target were longer when the target was unfamiliar. In contrast, when cues did not match the target (on invalid trials), cues increased fixation durations to distractors matching the cue. This is consistent with the cue modulating how easy it was to reject selected distractors (rejection was hard when the selected distractor matched the cue).

Cross-experimental analysis: First target-fixations on neutral trials

The analyses of first fixations to the target on neutral, uncued trials were inconsistent across experiments. In Experiment 2, there was a significant interaction between target familiarity and block, such that more first fixations were to familiar targets in block 4 versus block 1 which was not evident in Experiment 3. To gain a more complete and more powerful assessment, a cross-experiment analysis was undertaken on the frequency of fixations to the target, with the only adjustment being that for Experiments 1 and 2 yellow target data were coded as familiar targets, and for Experiment 3, purple target data were coded as familiar targets.

A four-factor, mixed-design ANOVA was undertaken (block, array size, target familiarity, experiment). There were main effects of effect of block $(\mathrm{F}(1,61)=81.949, \mathrm{p}<.001$, partial $\left.\eta^{2}=.573\right)$, target familiarity $(\mathrm{F}(1,61)=18.395, \mathrm{p}<$ .001 , partial $\left.\eta^{2}=.232\right)$, and experiment $(\mathrm{F}(2,61)=12.672, \mathrm{p}$ $<.001$, partial $\left.\eta^{2}=.294\right)$. There were more first fixations to the target on block 4 compared to block 1 (.179 vs. .063) and when the target carried a familiar color compared to when the color carried an unfamiliar color (.148 vs. .094). There were more first fixations to the target in Experiment 3 than both Experiment 1 and Experiment 2 (differences of .123, p < 


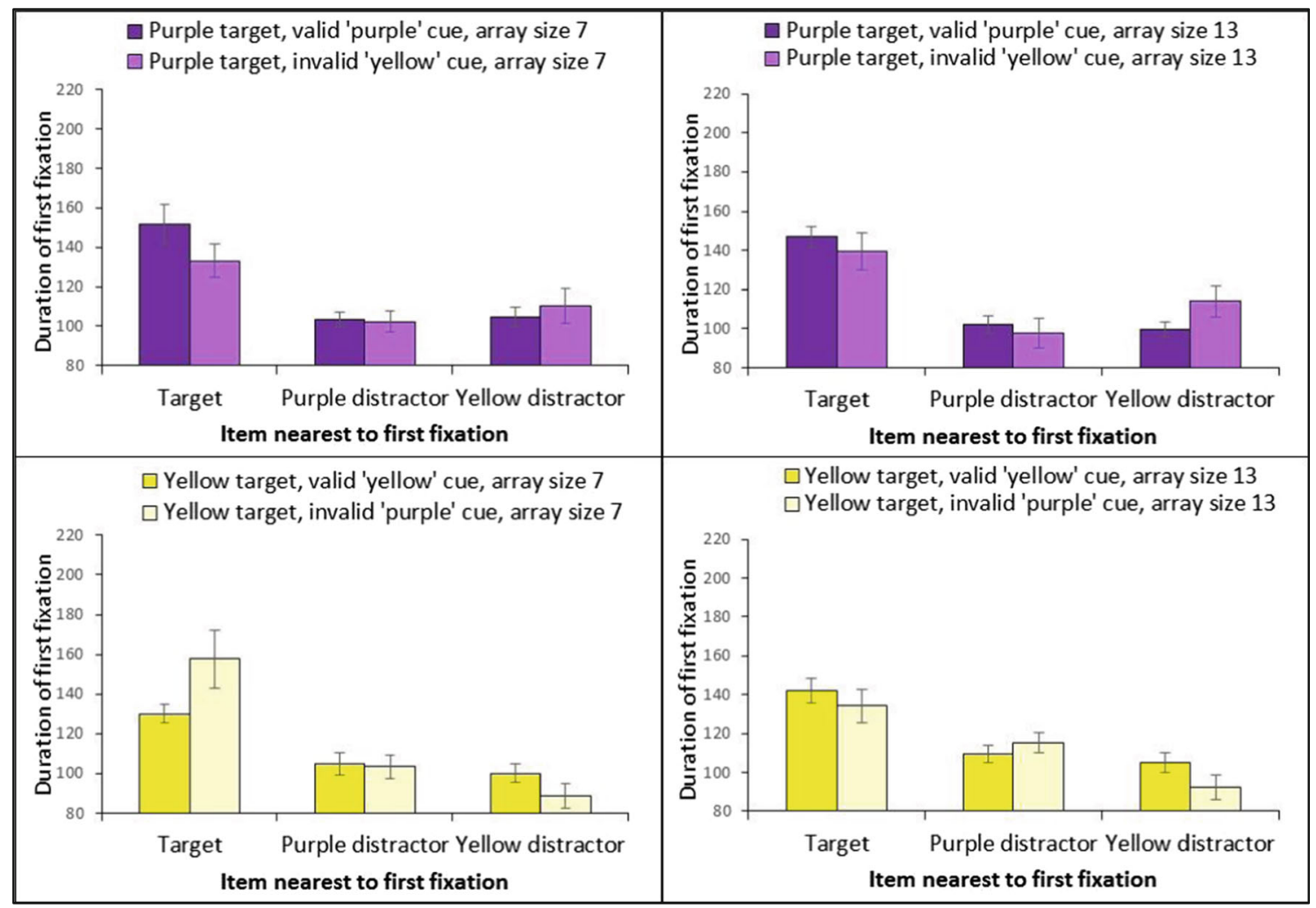

Fig. 15 Mean durations ( \pm 1 standard error) of first fixations in Experiment 3, split by item fixated, cue validity, and array size

.001 , and $.096, \mathrm{p}=.001$, respectively). The difference between Experiments 1 and 2 did not approach significance (a difference of $.027, p=.903)$. There was also a block $\times$ target familiarity interaction $\left(\mathrm{F}(1,61)=8.968, \mathrm{p}=.004\right.$, partial $\left.\eta^{2}=.128\right)$. Fixations to familiar targets increased across blocks to a greater extent that unfamiliar targets (differences of .141, $\mathrm{p}<.001$, and $.09, \mathrm{p}<.001$, respectively), leading to a larger bias in first fixations to familiar relative to unfamiliar targets in block 4 (a difference of $.08, \mathrm{p}<.001$ ) than in block 1 (a difference of $.029, \mathrm{p}=.032$ ).

\section{Discussion}

Despite switching the target and distractors (and so the color of the familiar targets, see Fig. 1), the findings replicated those of Experiment 2. In the absence of cues (e.g., neutral trials), search in block 1 was quicker and more efficient when the aubergine target carried its familiar color (purple) than when it was an unfamiliar color (yellow). There were also more first fixations to correctly colored targets, even in block 1 (replicating Experiment 1). After the two blocks of cued trials (e.g., in block 4), moreover, search remained facilitated for purple targets, but now search efficiency was matched across targets. Eye-tracking data indicated that participants make more first and second fixations to purple targets and this result held across different array sizes. The advantage for fixating purple over yellow targets increased on second fixations.

On cued trials, valid cues improved search speed and efficiency relative to invalid cues and there was a greater cost to search for unfamiliar targets on invalid trials. The eye movement data indicated that invalid cues directed search away from the target; however on invalid trials, first fixations were more likely to go to the purple than the yellow target - indeed first fixations to the invalid purple target were as frequent as those to a validly cued yellow target (see Fig. 14). Invalid cues also increased the duration of first fixations to distractors matching the cue, indicating top-down expectancies delayed the rejection of stimuli carrying cued color properties.

\section{General discussion}

We have demonstrated an advantage in search for objects carrying their familiar relative to an unfamiliar color, and an asymmetrical effect of cueing attention to the likely color of the target on a trial. While valid cues improved search for targets carrying unfamiliar colors, invalid cues disrupted search efficiency differentially for these targets. The benefits for targets in familiar colors generally emerged on first as well as second fixations made to the search displays and the effects 
were additive with the display size. The effect of cueing the color of the target was also independent of target color.

On neutral, uncued trials, search for a target in an unfamiliar color was relatively slow, with search efficiency matching that often found in search for color-form conjunctions ( $24 \mathrm{~ms} /$ item). Despite this evidence for apparently serial search, target selection was influenced by the familiarity of the target's color. Furthermore, the effects of target color familiarity on initial eye movements did not interact with the display size. This last result is consistent with bottom-up cueing of attention to stimuli carrying their familiar color. This may be complemented too by greater top-down guidance of attention, as targets in their familiar color are more likely to be fixated on the second saccade. However, there was little evidence for this in the results of Experiment 2, when participants were cued to expect a target in a particular color. Whilst there was little effect of cue validity on first fixations to the target, more second fixations were directed to targets in expected rather than unexpected colors (on valid vs. invalid trials). This "validity effect" did not interact with the familiarity of the color for the target, with targets in their familiar color benefitting (relative to targets in unfamiliar colors) on valid and invalid trials alike. This argument is against target color-familiarity arising from top-down biases and is supported by the results from Rappaport et al. (2013). They used biased probability conditions in which targets were expected in a particular unfamiliar color more than their expected color. Despite this, there remained an advantage for targets in the familiar color. On the other hand there was evidence for eye movements being directed to distractors carrying the familiar color of the target, suggesting that top-down factors did modulate search.

\section{Implications}

As noted in the Introduction, the influential Feature Integration Theory holds that visual search is constrained by the demands of binding together color and shape (Treisman, 1998). According to this theory, color and shape features are processed independently in a spatially parallel manner and they only become bound when attention is applied to their common location. Given that search for an unfamiliar color target here was relatively inefficient, there are grounds to argue that the target could not be distinguished from distractors without the application of attention. It follows that the colors and the shapes should only be bound once items are attended, and so the familiarity of the color-shape relationship should not affect search efficiency. This was clearly not the case (see also Rappaport et al., 2013). Moreover, our data indicate that the advantage for targets in their familiar color arises even when participants are cued to expect the item in another color and the effect is independent of the display sizes used here. Although this "familiarity advantage" is reduced when cue and target match in color, we posit that the results are consistent with bottom-up coding of the familiar shape-color conjunctions taking place in parallel across the display sizes used here.

The data are consistent with familiar color-form conjunctions being stored and acting to direct search. This fits with evidence on the reduced demands on parietal cortex, linked to spatial attention, once color-form conjunctions are learned (Walsh, Ellison, Ashbridge, \& Cowey, 1999) and with physiological evidence for learned conjunctive relations in visual cortical regions (Rust \& DiCarlo, 2010; Seymour, Clifford, Logothetis, \& Bartels, 2009, 2010). Once learned, the relationships between color and form can be detected directly by activating these conjunctive representations in a bottom-up manner. The idea that learned conjunctions are coded does fit with alternative accounts of attention and search, such as Attentional Engagement Theory (AET; Duncan \& Humphreys, 1989). AET is comfortable with the proposal that we have stored conjunction representations for stimuli (see also Humphreys \& Müller, 1993, for simulations), which can be activated in a spatially parallel manner. Our finding that first fixations tended to be directed to learned conjunction targets irrespective of the display size fits with this. In AET the efficiency with which a target can be selected would then depend on the similarity of its features to other items in a display - but having a learned representation for a particular conjunction of features should convey a search advantage even if distractors share features with targets.

In addition to the evidence for bottom-up effects, we did find that the effects of top-down invalid cueing were stronger on unfamiliar relative to familiar targets (Experiments 2 and 3). That is, unfamiliar targets were particularly difficult to find if participants were cues to expect a target in a familiar color. This result suggests the set for an expectation for a familiar target may be particularly difficult to shift, once formed. In some sense, then, this can reflect a top-down impact on search, determining not the first selection of an item but the switch from that item to re-engage attention on a target. It will be interesting to assess this top-down disengagement component, its properties and time course, in future work.

\section{Summary}

Our findings indicate that search for a shape target automatically activates the color associated with that shape, and that this can modulate search in both a top-down and bottom-up manner. When stored knowledge for the target is used to direct search, information about the target's known color is employed as part of the search set. However, even when expectancies are set for another color there are no costs on search 
efficiency for targets in their familiar color, indicating effects on bottom-up as well as top-down guidance of search. An alternative, but not mutually exclusive, view is that familiar shape-color binding takes place through synchronized neural firing of neurons sensitive respectively to shape and color (e.g., Gray \& Singer, 1989). Here one would argue that neural synchronisation is facilitated by learning that a particular color and shape frequently co-occur.

Reinforcing the functional connectivity between a shape and a color, based on frequent co-occurrences, may help instantiate synchronized neural activity, binding the color to the shape. Exactly how familiar shapes and colors come to be bound in a spatially parallel manner is an important question for future research.

\section{References}

Anderson, G. M., Heinke, D., \& Humphreys, G. W. (2013). Top-down Guidance of Eye Movements in Conjunction Search. Vision Research, 79(1), 36-46.

Belke, E., Humphreys, G. W., Watson, D. G., Meyer, A. S., \& Telling, A. L. (2008). Top-down Effects of Semantic Knowledge in Visual Search are Modulated by Cognitive but not Perceptual Load. Perception \& Psychophysics, 70, 1444-1458.

Duncan, J., \& Humphreys, G. W. (1989). Visual Search and Stimulus Similarity. Psychological Review, 96(3), 433-458.

Gray, C. M., \& Singer, W. (1989). Stimulus-specific neuronal oscillations in orientation columns of cat visual cortex. Proceedings of the National Academy of Sciences, 86(5), 1698-1702.

Humphreys, G. W., \& Müller, H. J. (1993). SEarch via Recursive Rejection (SERR): A Connectionist Model of Visual Search. Cognitive Psychology, 25(1), 43-110.

Iordanescu, L., Grabowecky, M., Franconeri, S., Theeuwes, J., \& Suzuki, S. (2010). Characteristic Sounds Make You Look at Target Objects More Quickly. Attention, Perception, \& Psychophysics, 72(7), 1736-1741.

Meeter, M., \& Theeuwes, J. (2006). Cuing the Dimension of a Distractor: Verbal Cues of Target Identity Also Benefit Same-dimension Distractor Singletons. Psychonomic Bulletin \& Review, 13(1), 118-124.

Moores, E., Laiti, L., \& Chelazzi, L. (2003). Associative Knowledge Controls Deployment of Visual Selective Attention. Nature Neuroscience, 6(2), 182-189.
Müller, H. J., Heller, D., \& Ziegler, J. (1995). Visual Search for Singleton Feature Targets Within and Across Feature Dimensions. Perception \& Psychophysics, 57, 1-17.

Posner, M. I. (1980). Orienting of Attention. The Quarterly Journal of Experimental Psychology, 32(1), 3-25.

Rappaport, S. J., Humphreys, G. W., \& Riddoch, M. J. (2013). The Attraction of Yellow Corn: Reduced Attentional Constraints on Coding Learned Conjunctive Relations. Journal of Experimental Psychology: Human Perception and Performance, 39(4), 1016-1031.

Rust, N. C., \& DiCarlo, J. J. (2010). Selectivity and Tolerance ("Invariance") Both Increase as Visual Information Propagates from Cortical Area V4 to IT. Journal of Neuroscience, 30(39), 12978-12995

Salthouse, T. A., \& Ellis, C. L. (1980). Determinants of eye-fixation duration. American Journal of Psychology, 93, 207-234.

Seymour, K., Clifford, C. W. G., Logothetis, N. K., \& Bartels, A. (2009). The Coding of Color, Motion, and Their Conjunction in the Human Visual Cortex. Current Biology, 19(3), 177-183.

Seymour, K., Clifford, C. W. G., Logothetis, N. K., \& Bartels, A. (2010). Coding and Binding of Color and Form in Visual Cortex. Cerebral Cortex, 20(8), 1946-1954.

Telling, A. L., Kumar, S., Meyer, A. S., \& Humphreys, G. W. (2009). Electrophysiological Evidence of Semantic Interference in Visual Search. Journal of Cognitive Neuroscience, 22(10), 2212-2225.

Treisman, A. (1998). Feature Binding, Attention and Object Perception. Philosophical transactions of the Royal Society of London. Series B, Biological Sciences, 353(1373), 1295-1306.

van Zoest, W., Donk, M., \& Theeuwes, J. (2004). The Role of StimulusDriven and Goal-Driven Control in Saccadic Visual Selection. Journal of Experimental Psychology: Human Perception and Performance, 30(4), 746-759.

Walsh, V., Ellison, A., Ashbridge, E., \& Cowey, A. (1999). The role of the parietal cortex in visual attention - hemispheric asymmetries and the effects of learning: a magnetic stimulation atudy. Neuropsychologia, 37, 245-251.

Wang, Q., Cavanagh, P., \& Green, M. (1994). Familiarity and pop-out in visual search. Perception \& Psychophysics, 56, 495-500.

Wildegger, T., Riddoch, M. J., \& Humphreys, G. W. (2015). Stored colorform knowledge modulates perceptual sensitivity in search. Attention, Perception \& Psychophysics, 77, 1223-1238.

Wolfe, J. M. (2003). Moving towards solutions to some enduring controversies in visual search. TRENDS in Cognitive Sciences, 7(2), 70 75.

Wolfe, J. M., Cave, K. R., \& Franzel, S. K. (1989). Guided search: an alternative to feature integration model for visual search. Journal of Experimental Psychology: Human Perception and Performance, $15,419-433$. 